\title{
Pharmacological management of binge eating disorder: current and emerging treatment options
}

This article was published in the following Dove Press journal:

Therapeutics and Clinical Risk Management

7 May 2012

Number of times this article has been viewed

\author{
Susan L McElroy \\ Anna I Guerdjikova \\ Nicole Mori \\ Anne M O'Melia \\ Lindner Center of HOPE, Mason, and \\ Department of Psychiatry, University \\ of Cincinnati College of Medicine, \\ Cincinnati, OH, USA
}

\begin{abstract}
Growing evidence suggests that pharmacotherapy may be beneficial for some patients with binge eating disorder (BED), an eating disorder characterized by repetitive episodes of uncontrollable consumption of abnormally large amounts of food without inappropriate weight loss behaviors. In this paper, we provide a brief overview of BED and review the rationales and data supporting the effectiveness of specific medications or medication classes in treating patients with BED. We conclude by summarizing these data, discussing the role of pharmacotherapy in the BED treatment armamentarium, and suggesting future areas for research.
\end{abstract}

Keywords: binge eating disorder, pharmacotherapy, medication management

\section{Introduction}

Binge eating disorder (BED) is an eating disorder characterized by recurrent, distressing binge-eating episodes without the inappropriate compensatory weight loss behaviors of bulimia nervosa. ${ }^{1,2}$ Increasing research indicates BED is an important public health problem. It is common, with an estimated lifetime prevalence in the US and Western Europe of $1 \%-3 \%{ }^{3,4}$ In addition, BED is increasing in prevalence, is often chronic, and is associated with psychiatric comorbidity, obesity and other medical conditions, and disability. ${ }^{3,5-9}$

The therapeutic armamentarium for BED is growing, but treatment remains a challenge (Table 1). ${ }^{10,11}$ Specialized psychotherapies, in particular cognitive behavior therapy (CBT) and interpersonal therapy, and self-help strategies are effective for reducing binge eating, but not all patients respond adequately. ${ }^{10,12}$ Moreover, these treatments are generally not effective for the obesity associated with BED, and patients with more complex yet common comorbid comorbidities, such as bipolar disorder, severe personality disorders, or unstable diabetes or hypertension, have been excluded from study participation, raising questions about the generalizability of treatment effectiveness. On the other hand, bariatric surgery may reduce binge eating and induce clinically significant weight loss in obese patients with BED. ${ }^{13}$ However, the literature is inconsistent as to how binge eating affects response to bariatric surgery, with some studies indicating that binge eating is associated with less weight loss and more subsequent weight regain. ${ }^{14-16}$ Moreover, a sizeable proportion of surgical patients have binge eating episodes approximately 2 years after surgery. ${ }^{17}$ Therefore, novel treatments are needed for BED.

A number of reviews ${ }^{18-24}$ and guidelines ${ }^{25-27}$ have recently discussed the role pharmacotherapy might play in treating patients with BED. However, no drug has been
Correspondence: Susan L McElroy Lindner Center of HOPE, 4075 Old

Western Row Road, Mason,

$\mathrm{OH} 45040$, USA

$\mathrm{Tel}+\mathrm{I} 5135360700$

Fax +I 5135360709

Email mcelrosı@ucmail.uc.edu
Therapeutics and Clinical Risk Management 20I2:8 219-24I

(C) 2012 McElroy et al, publisher and licensee Dove Medical Press Ltd. This is an Open Access article

Dovepress

http://dx.doi.org/10.21 477/TCRM.S25574 
Table I Nonpharmacological treatments for BED

\begin{tabular}{|c|c|}
\hline Modality ${ }^{a}$ & Qualitative findings \\
\hline \multicolumn{2}{|l|}{ Psychotherapy } \\
\hline \multirow[t]{2}{*}{ Cognitive behavioral therapy } & Decreases binge eating behavior, associated eating disorder psychopathology, and depressive symptoms. \\
\hline & Does not result in clinically meaningful weight loss. Antibinging benefits maintained on follow-up. \\
\hline \multirow[t]{2}{*}{ Interpersonal therapy } & Decreases binge eating behavior, associated eating disorder psychopathology, and depressive symptoms. \\
\hline & Does not result in clinically meaningful weight loss. Antibinging benefits maintained on follow-up. \\
\hline Dialectical behavior therapy & $\begin{array}{l}\text { Decreases binge eating behavior and associated eating disorder psychopathology without producing clinically } \\
\text { meaningful weight loss. }\end{array}$ \\
\hline Behavioral weight loss & $\begin{array}{l}\text { May reduce binge eating behavior and associated eating pathology in some patients. Often produces short-term } \\
\text { weight loss. Might be suitable for BED patients without high levels of specific eating disorder psychopathology. }\end{array}$ \\
\hline Self-help ${ }^{b}$ & $\begin{array}{l}\text { Decreases binge eating behavior and eating disorder psychopathology but does not result in clinically } \\
\text { meaningful weight loss. }\end{array}$ \\
\hline Combination treatments ${ }^{c}$ & $\begin{array}{l}\text { Decreases binge eating behavior and associated eating disorder psychopathology without producing clinically } \\
\text { meaningful weight loss. }\end{array}$ \\
\hline Bariatric surgery & $\begin{array}{l}\text { Decreases binge eating behavior and eating disorder psychopathology along with producing clinically significant } \\
\text { weight loss. Preoperative BED and postoperative loss of control eating may be associated with less weight loss } \\
\text { or more weight gain, but findings are mixed. }\end{array}$ \\
\hline
\end{tabular}

Notes: aRandomized controlled trials were preferentially evaluated for this summary, when available; bincludes CBT self-help, guided CBT self-help, CBT partial self-help, and telephone-based guided self-help; 'includes studies of CBT plus weight loss treatment; CBT plus nutritional counseling; and CBT plus physical activity.

Abbreviations: $\mathrm{BED}$, binge-eating disorder; $\mathrm{CBT}$, cognitive behavioral therapy.

approved by the US Food and Drug Administration or any other regulatory agency for the treatment of this condition. Moreover, there has been little discussion as to where pharmacotherapy fits into the therapeutic armamentarium for BED.

In this review, we first provide a brief overview of BED and the rationales for using medication in the treatment of this condition. We then review the data supporting the effectiveness of specific medications or medication classes in treating patients with BED. We conclude by summarizing these data and discussing the role pharmacotherapy might play in the treatment of BED. We also suggest future areas for research in BED pharmacotherapy.

\section{Overview of binge eating disorder}

BED is the most common eating disorder in the US, with a lifetime prevalence of $2.5 \%$ in adults ${ }^{3}$ and $1.6 \%$ in adolescents. ${ }^{28}$ It has both similarities to and differences from bulimia nervosa. ${ }^{2,29}$ Like bulimia nervosa, a core feature is recurrent, distressing binge eating episodes. Binge eating episodes are defined in the Diagnostic and Statistical Manual of Mental Disorders, 4th Edition (DSM-IV) as: eating in a discrete period of time an amount of food that is definitely larger than most people would eat in a similar period under similar circumstances and with a sense of lack of control over eating during the episode. ${ }^{1}$ The regular occurrence of inappropriate compensatory behaviors characteristic of bulimia nervosa do not occur in BED, though some patients engage in such behaviors infrequently. Like bulimia nervosa, BED is more common in females, associated with shape and weight concerns in addition to binge eating, may be chronic, and is associated with elevated rates of mood, anxiety, and substance use disorders. ${ }^{2}$ However, in bulimia nervosa, whereas dieting often precedes binge eating, binge eating may antedate sporadic attempts to control weight in BED ${ }^{29,30}$ Laboratory studies indicate binge eating episodes may be smaller in BED than in bulimia nervosa, ${ }^{31}$ while preliminary psychological and neuroimaging findings suggest that BED is disproportionally associated with increased reward sensitivity and stronger medial orbitofrontal cortex responsivity while viewing food compared with patients suffering from bulimia nervosa and healthy controls..$^{32}$ Also, in contrast with bulimia nervosa, BED is more common in males, has a later age of onset in adult cohorts, and is more often associated with obesity. ${ }^{3}$ For example, in the National Comorbidity Survey Replication, the mean \pm standard deviation age of onset for BED was $25.4 \pm 1.2$ years as compared with $19.7 \pm 1.3$ years for bulimia nervosa. ${ }^{3}$ In addition, $42 \%$ of individuals with BED were obese (as defined by a body mass index $[\mathrm{BMI}] \geq 30 \mathrm{mg} / \mathrm{kg}^{2}$ ), with $15 \%$ having a $\mathrm{BMI} \geq 40 \mathrm{mg} / \mathrm{kg}^{2}$, as compared with $31 \%$ and $10 \%$, respectively, for individuals with bulimia nervosa. ${ }^{3}$

BED overlap with obesity is so extensive that some have questioned whether they are truly distinct entities. ${ }^{29}$ However, not all individuals with BED are overweight or obese. ${ }^{33}$ In addition, compared with obese individuals without BED, obese individuals with BED have greater concerns about shape and body weight and greater body dissatisfaction, report lower quality of life, consume more calories in laboratory-based studies, have greater cognitive deficits on 
neuropsychological testing, have higher rates of comorbid Axis I and Axis II disorders, have higher rates of mood disorders and obesity in first-degree relatives, and may have a distinct neurobiology. 2,6,34-37

These converging lines of evidence have led to the consensus that BED is a valid eating disorder subtype distinct from bulimia nervosa and obesity, and to the recommendation that it be elevated from inclusion in the DSM-IV appendix to a formal disorder in DSM-5., 2,38,39 Research showing BED individuals who binge eat once per week are comparable with those who binge at least twice per week has led to the proposal that recurrent binge eating need occur at least once a week for 3 months, similar to that in bulimia nervosa, to meet the new proposed DSM- 5 criteria for BED. ${ }^{40}$ It has been suggested this modification should not substantially change prevalence estimates of BED. ${ }^{41}$

\section{Rationale for using pharmacotherapy in treating binge eating disorder}

There are several rationales for using pharmacotherapy to treat BED. First, mounting evidence indicates that BED, like other eating disorders and the mood, anxiety, and substance use disorders it co-occurs with, is a mental disorder with genetic contributions and neurobiological abnormalities that causes distress and disability and does not always respond adequately to available psychological interventions. ${ }^{42}$ Some patients, including those with chronic or intractable illness, need medication for optimal outcomes. ${ }^{43}$

Second, as more is learned about the biology of eating behavior, disordered eating, and obesity, ${ }^{44}$ preclinical and neuroimaging work is beginning to elucidate a neurobiology of binge eating, especially for bulimia nervosa, but also for BED. ${ }^{45,46}$ Animal models of binge eating suggest potential involvement of opioid, dopamine, and norepinephrine systems, all of which influence feeding behavior. A recent positron emission tomographic study found dopamine dysfunction in the caudate of obese humans with BED as compared with obese humans without BED. ${ }^{37}$ Behavioral genetics research has suggested that the serotonin system may play a critical role, because mice lacking functional $5 \mathrm{HT}_{2 \mathrm{C}}$ receptors display marked hyperphagia, leading to the development of obesity. ${ }^{47}$ Preclinical work showing that alterations to the gastrointestinal tract can affect eating behavior also has implications for BED. Thus, BED is associated with gastric distension, ${ }^{48}$ and repeated gastric distension alters food intake and neuroendocrine profiles in rats. ${ }^{49}$ Additionally, BED might be associated with other abnormalities external to the central nervous system, such as in adipose tissue-derived hormones. ${ }^{34}$ Understanding the neurobiology of BED will promote development of targeted pharmacotherapies.

A third reason is that many available medications have effects on appetite and weight that may translate into therapeutic effects in BED. Thus, antiobesity agents (eg, phentermine and orlistat), stimulants, some antidepressants (bupropion), some antiepileptic drugs (eg, topiramate and zonisamide), and some drugs for type 2 diabetes (eg, exenatide, liraglutide) are associated with decreased appetite and/or weight loss. ${ }^{50-52}$ Examples of neurotransmitter systems involved in the regulation of feeding behavior and weight control affected by these drugs include the biogenic amines serotonin, norepinephrine, and dopamine (eg, by antidepressants, stimulants, and zonisamide) and the major excitatory transmitter glutamate (eg, by topiramate). ${ }^{53-55}$ Affected peptides involved in controlling feeding and body weight include neuropeptide $\mathrm{Y}$ (eg, by topiramate and zonisamide), ${ }^{56-58}$ amylin (by pramlintide), and glucagon-like peptide-1 (by exenatide and liraglutide). ${ }^{44,52,59,60}$ Growing research suggests medications with anorectic or weight loss effects may be helpful for patients with BED. ${ }^{61,62}$ Moreover, novel pharmaceutical compounds for mood and other mental disorders, obesity and diabetes, and epilepsy will likely continue to come to market. ${ }^{63-68}$ Some of these agents may prove to have beneficial effects on appetite or weight regulation, and ultimately therapeutic effects in patients with BED.

\section{Literature search}

PubMed was searched up to February 2012 using the following terms: "binge eating", "binge eating disorder", "eating disorder not otherwise specified", "nonpurging bulimia nervosa", "pharmacotherapy", “antidepressants", “antiepileptics", "antiobesity", "antipsychotics", "mood stabilizers", "opioid antagonists", and "stimulants". We also used the terms of the following individual medications: "acamprosate", "amphetamine", “atomoxetine", "exenatide", "fenfluramine", "lamotrigine", "liraglutide", "methylphenidate", "naltrexone", "pramlintide", "sibutramine", "topiramate", and "zonisamide". Our search was supplemented by review of reference lists of relevant articles.

\section{Pharmacotherapy}

We located 22 prospective, randomized, placebo-controlled pharmacotherapy studies of BED or closely related syndromes (Tables 2-4). Most trials were short-term (6-16 weeks) and all were conducted in adults who were actively binge eating. The majority of studies excluded patients with serious or 


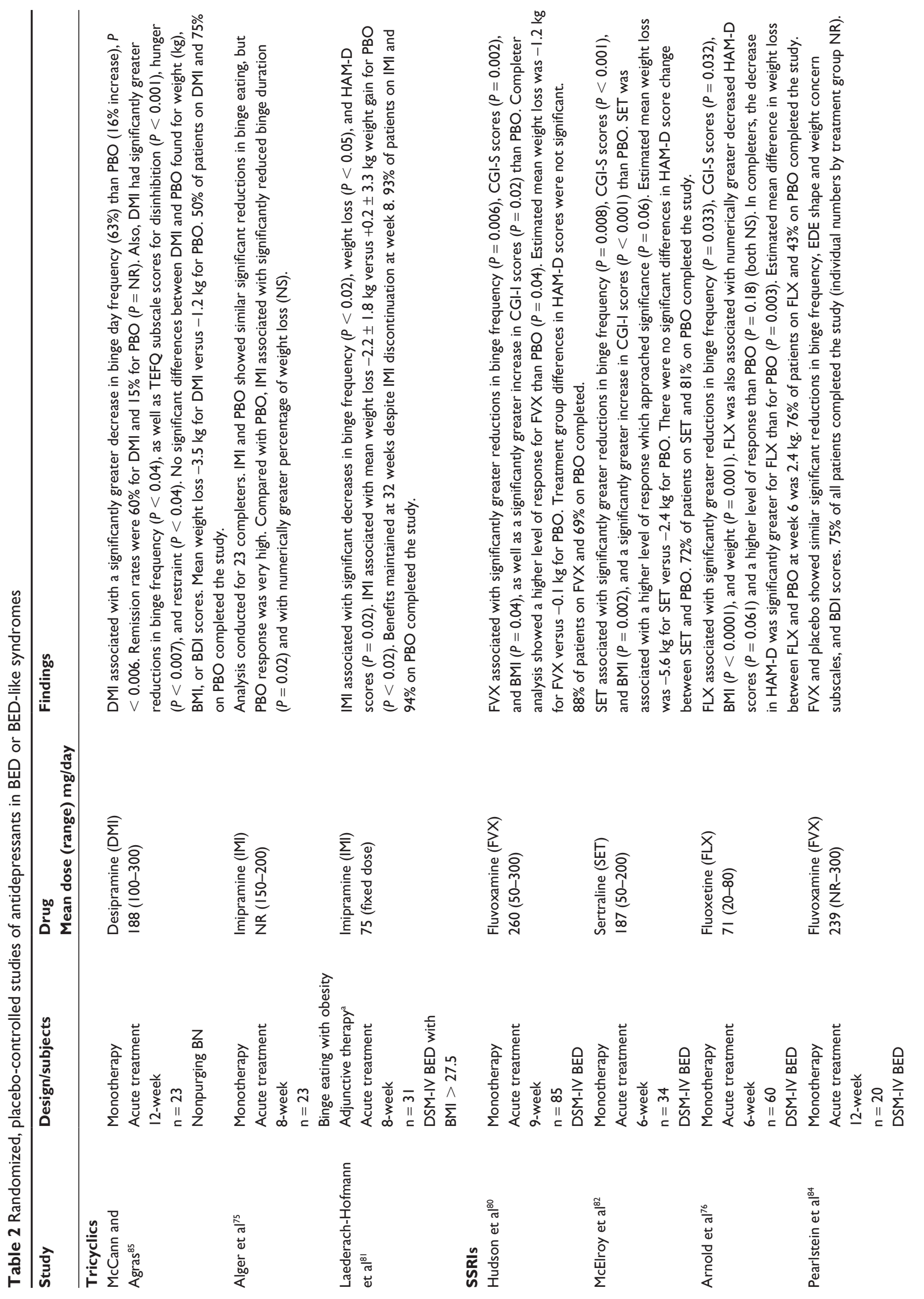



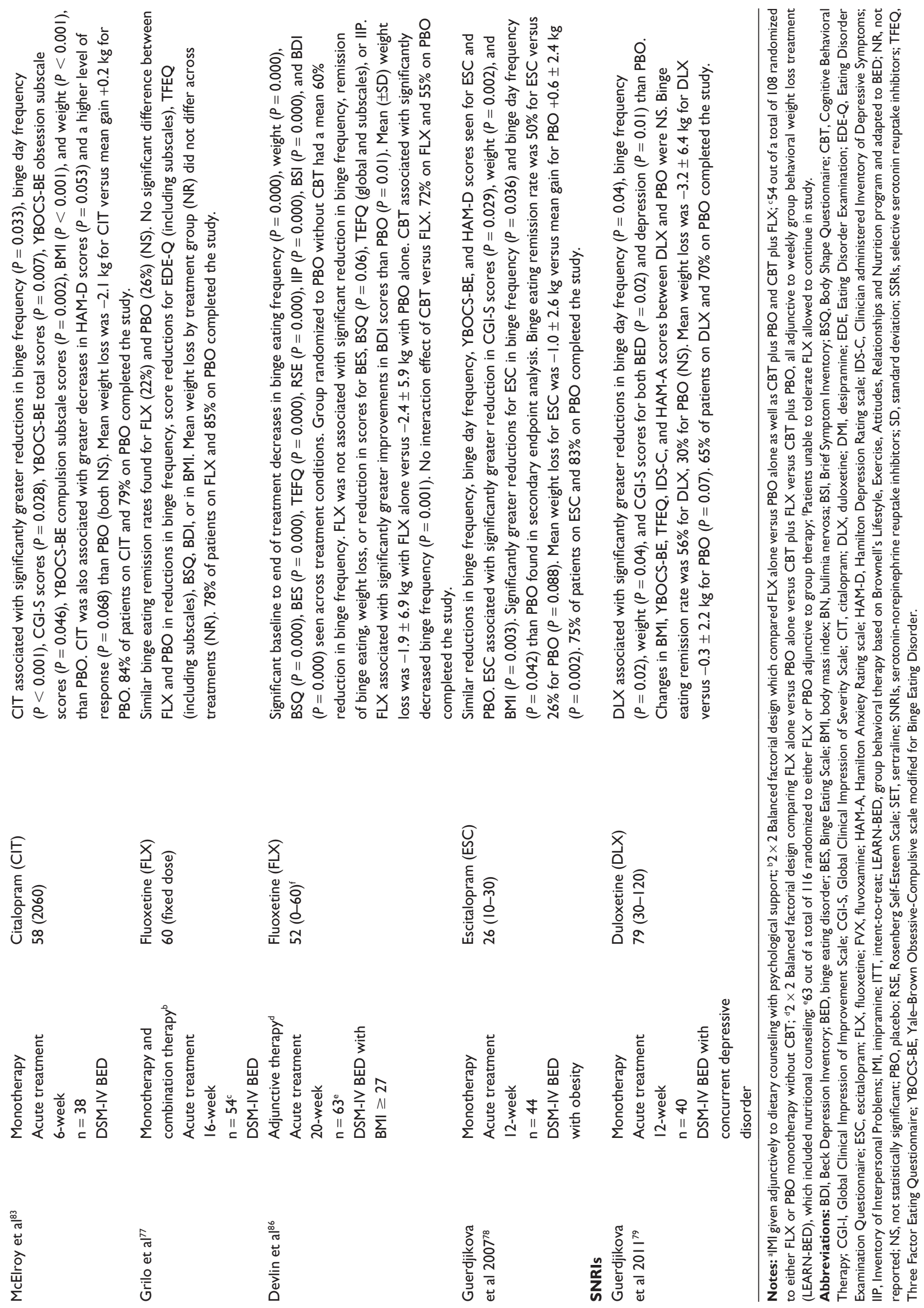


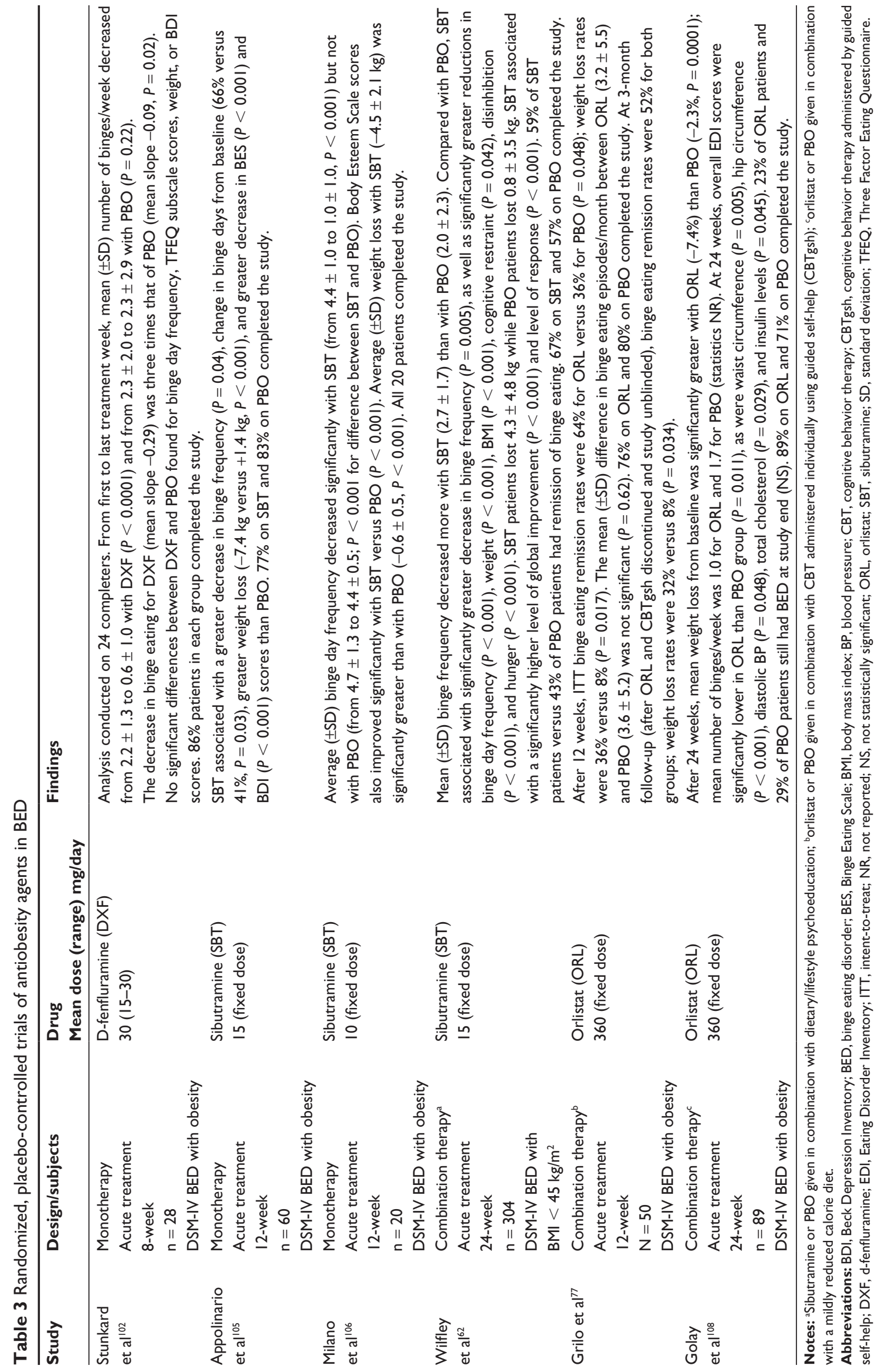




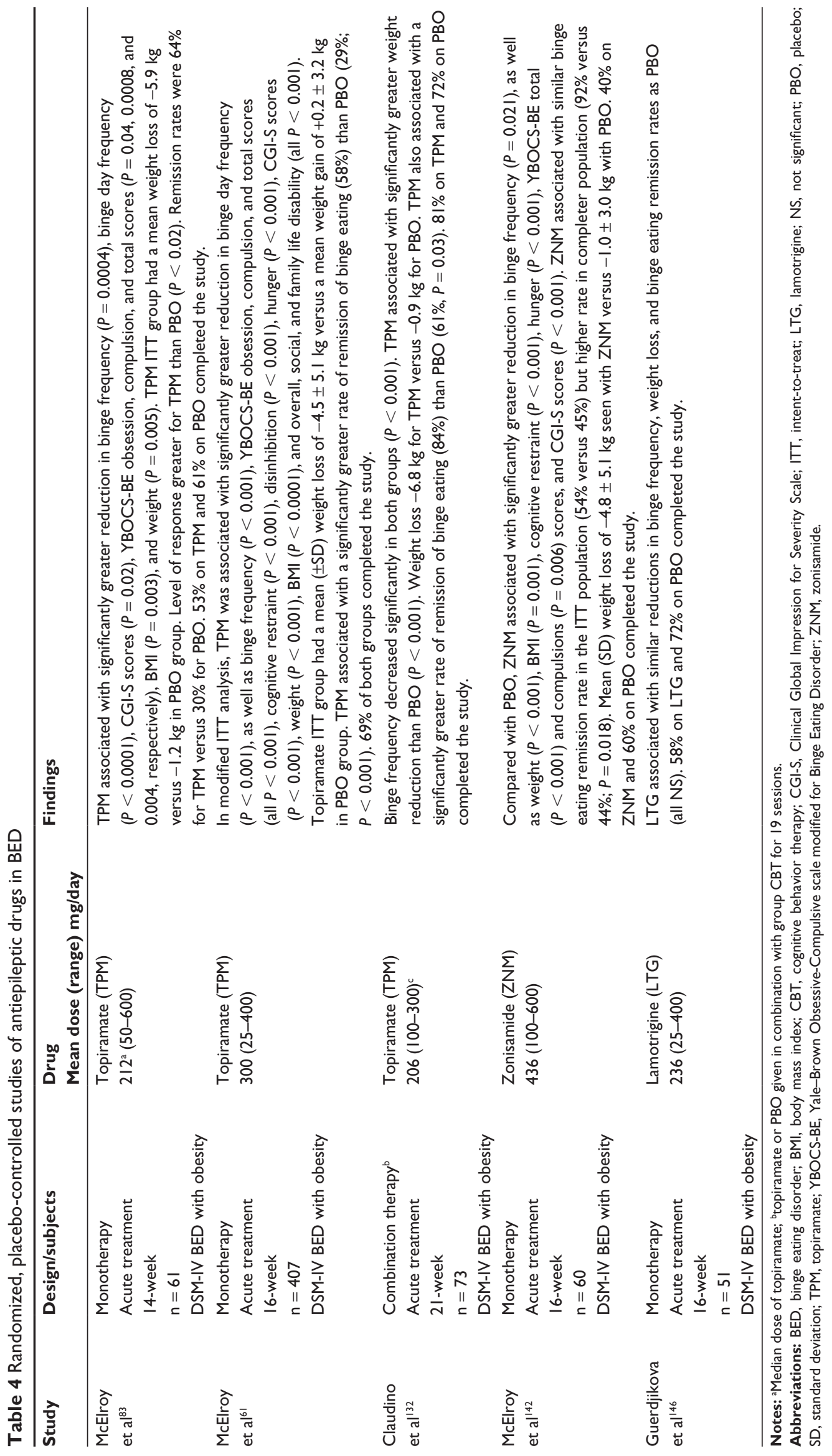


unstable comorbid psychiatric or medical disorders such as bipolar disorder, substance use disorders, diabetes, and hypertension or other forms of cardiovascular disease. Many studies were monotherapy trials where medication alone was compared with placebo alone. Fewer studies were combination or adjunctive therapy trials in which medication plus a psychological intervention was compared with placebo plus the psychological intervention.

The primary outcome was usually a measure of the frequency of binge eating episodes (binge frequency) or binge days (binge day frequency), or the rate of remission or response of binge eating behavior. Less frequently, the primary outcome was weight loss. Secondary outcome measures have included general eating disorder psychopathology; global clinical improvement; mood, anxiety, obsessivecompulsive, and impulsive symptoms; body weight, BMI, and other metabolic parameters; and adherence with study medication.

The medications studied thus far in BED in randomized, placebo-controlled studies have been conducted primarily with three drug classes, ie, antidepressants, antiobesity agents, and antiepileptic drugs. ${ }^{25,42,69}$ Drug classes that have received less study include antiaddiction (or anticraving) agents and drugs used for attention deficit hyperactivity disorder. The individual studies are reviewed in the following text according to drug class, along with the rationales prompting their study in BED.

\section{Antidepressants}

Several rationales led to studies of antidepressants in BED. First is that BED is characterized by binge eating similar to that of bulimia nervosa, and antidepressants are efficacious in bulimia nervosa. ${ }^{18,70}$ Tricyclics, monoamine oxidase inhibitors, selective serotonin reuptake inhibitors (SSRIs), and several atypical agents (mianserine, trazodone, and bupropion) $)^{71}$ have all been shown to be superior to placebo for reducing the frequency of both binge eating and purging episodes in bulimia nervosa. ${ }^{23,70,72}$ Indeed, the antidepressant fluoxetine is the only medication approved by the Food and Drug Administration for the treatment of an eating disorder, that being bulimia nervosa. Second is that BED co-occurs with other disorders that are responsive to antidepressants, including major depressive disorder, panic disorder, generalized anxiety disorder, and obsessive-compulsive disorder. ${ }^{3}$ Third is that BED may be associated with abnormalities in serotonin, norepinephrine, and dopamine which are targeted by most antidepressant classes. ${ }^{37,73,74}$ To date, at least 12 prospective, randomized, placebo-controlled studies of antidepressants have been published in patients with BED as defined by all or most of the DSM-IV criteria. ${ }^{75-86}$ Nine studies evaluated antidepressant monotherapy while three compared antidepressants in combination with weight loss therapy, ${ }^{81} \mathrm{CBT},{ }^{87}$ or both. ${ }^{86}$ Eight trials evaluated SSRIs, three evaluated tricyclics, and one evaluated a serotonin-norepinephrine reuptake inhibitor. The latter assessed duloxetine in BED patients with co-occurring depressive disorders. ${ }^{79}$ All studies were small, consisting of 20-85 patients, of short duration, ranging from 6 to 20 weeks, and many were associated with substantial dropout rates. Some were also associated with high placebo response rates. ${ }^{75}$ Tricyclic doses were low as compared with those used in depression; SSRI doses were higher, comparable with those recommended for bulimia nervosa (ie, $60 \mathrm{mg}$ daily of fluoxetine). A study of fluoxetine used doses up to $80 \mathrm{mg} /$ day $^{76}$ and a study of escitalopram used supratherapeutic doses (up to $30 \mathrm{mg} /$ day). ${ }^{78}$

When viewed collectively, SSRIs led to greater rates of reduction in target binge eating, psychiatric, and weight symptoms than placebo. ${ }^{21,88}$ However, most weight reductions would not be considered clinically significant. Tricyclic antidepressants were inconsistent regarding reductions in binge eating and weight loss. Duloxetine led to decreased binge eating, weight loss, and global improvement in eating disorder and depressive symptoms. ${ }^{79}$

A meta-analysis of seven of these studies (one with a tricyclic antidepressant, six with SSRIs) showed significantly higher binge eating remission rates for the antidepressant group compared with the placebo group: $40.5 \%$ versus $22.2 \%$ (relative risk [RR] $0.77 ; 95 \%$ CI $0.65-0.92 ; P=0.003) .{ }^{89}$ Evaluating studies that used the Hamilton Depression Rating Scale to evaluate change in depressive symptoms, a statistically significant difference between groups was also seen favoring antidepressants (standardized mean difference $-0.38 ; 95 \% \mathrm{CI}-74,-0.03 ; P=0.03$ ). However, no differences between groups were found in the mean frequency of binge eating episodes at the end of treatment (standardized mean difference -0.36 ; 95\% CI $-0.74-0.01$; $P=0.06$ ), in BMI (standardized mean difference $0.03 ; 95 \%$ CI -0.49-0.55), or in treatment discontinuation for any reason (RR 1.35; 95\% CI 0.61-3.00). The authors concluded that, in light of the frequent chronicity of BED, the data were not sufficient to recommend antidepressants formally as a single first-line therapy for short-term remission of binge eating episodes and weight reduction in BED patients.

Controlled combination therapy studies have had contrasting results. In one, diet counseling with psychological support plus imipramine was superior to diet counseling and 
psychological support plus placebo for 8 weeks in decreasing binge eating $(P<0.01)$ and weight $(P<0.001) .{ }^{81}$ Benefits were maintained at 8-month follow-up despite discontinuation of imipramine. In another 16-week trial, CBT with placebo and CBT with fluoxetine were both superior to fluoxetine alone and placebo alone for decreasing binge eating. ${ }^{77}$ There was no difference between fluoxetine and placebo, though patients who responded early to fluoxetine continued to do well, while lack of early response was associated with failure to achieve remission. ${ }^{90}$ There was no additive effect for the combination of fluoxetine plus CBT over CBT alone for decreasing binge eating, and no single or combined treatment was effective for weight loss. In the third study, 116 patients with BED receiving group behavioral weight control treatment for 20 weeks were randomized twice to adjunctive CBT or no CBT and to fluoxetine $40-80 \mathrm{mg}$ daily or placebo. ${ }^{86} \mathrm{CBT}$, but not adjunctive fluoxetine, was effective for reducing binge eating. However, fluoxetine was effective for decreasing depressive symptoms. Neither CBT alone, fluoxetine alone, nor their combination were effective for weight loss.

Two randomized, placebo-controlled trials showed that SSRIs (fluvoxamine and fluoxetine) may be modestly effective in reducing relapse to binge eating in bulimia nervosa, ${ }^{91,92}$ but comparable relapse prevention studies of antidepressant monotherapy in BED have not yet been conducted. Open-label data have suggested that some patients with BED who initially respond to SSRIs with decreased binge eating and weight loss may maintain these beneficial effects for up to 6 months with continuation of the SSRI. ${ }^{93,94}$ On the other hand, a 2-year follow-up study found that fluoxetine continued to be ineffective for binge eating or weight reduction after it was ineffective during an initial 5-month phase, though the drug remained effective for depressive symptoms. ${ }^{86,95}$ Of note, $77 \%$ of patients in this study receiving medication were unblinded before or at the end of the initial 5-month phase of treatment.

Several promising antidepressants have not yet been studied in BED in randomized, placebo-controlled trials. These include bupropion, the serotonin-norepinephrine reuptake inhibitors venlafaxine, desvenlafaxine, and milnacipran, and the novel dual activity antidepressant, vilazodone, an SSRI and partial agonist at the serotonin $5 \mathrm{HT}_{1 \mathrm{~A}}$ receptor. According to ClinicalTrials.gov, a randomized, placebo-controlled trial of bupropion in binge eating disorder and obesity is ongoing (NCT00414167; retrieved April 25, 2012). Also, a retrospective clinical analysis has suggested that bupropion may be associated with greater weight loss than sertraline for BED patients. ${ }^{96}$ Another retrospective chart review found that venlafaxine was effective for reducing binge eating and body weight in 33 patients with BED and obesity. ${ }^{97}$ Vilazodone may be promising in light of its partial agonism at the serotonin $5 \mathrm{HT}_{1 \mathrm{~A}}$ receptor, and clarify the involvement of this receptor subtype in binge eating. ${ }^{98}$

\section{Antiobesity agents}

At least two rationales led to studies of antiobesity agents in BED. First is that BED is associated with obesity and antiobesity agents cause weight loss. Second is that antiobesity agents may have antibinge eating properties, either directly through appetite suppressant or satiety-enhancing properties or indirectly through metabolic effects. The antiobesity agents studied thus far for BED in randomized controlled trials have been sibutramine, orlistat, and d-fenfluramine (Table 3). Although sibutramine and d-fenfluramine have been removed from the worldwide market because of safety concerns, all three drugs will be reviewed for scientific completeness.

\section{Fenfluramine}

Fenfluramine and its isomer d-fenfluramine (the more selective dextro enantiomer of racemic d, 1-fenfluramine) are efficacious weight loss drugs with strong proserotonergic properties. D-fenfluramine inhibits the reuptake of serotonin, while its metabolite d-norfenfluramine is a potent serotonin reuptake inhibitor and serotonin releaser. ${ }^{99}$ The role of serotonin in enhancing satiety and the weight loss properties of d-fenfluramine led to one randomized controlled trial of the drug in BED before it was removed from the worldwide market in 1997 because of concerns that it caused cardiac valvular abnormalities and pulmonary hypertension. ${ }^{100,101}$ In that study, 28 women with BED and obesity received d-fenfluramine up to $30 \mathrm{mg} /$ day or placebo for 8 weeks. ${ }^{102}$ In the 24 women who completed the trial, the rate of binge eating fell three times more rapidly in the d-fenfluramine group than in the placebo group. However, no significant weight changes were observed. Nonetheless, 4 months after discontinuation of d-fenfluramine, binge eating had increased to pretreatment levels.

\section{Sibutramine}

Sibutramine is a reuptake inhibitor of norepinephrine, serotonin, and, to a lesser extent, dopamine, that is thought to cause weight loss by increasing satiety. ${ }^{103}$ It was removed from the worldwide market in 2010 because of an increased risk of myocardial infarction and stroke (but not death) 
found in obese or overweight persons with pre-existing cardiovascular disease. ${ }^{104}$

Three placebo-controlled studies, including one large multicenter trial, have been conducted with sibutramine (Table 3). In the first study, 60 patients with DSM-IV BED and obesity were randomly assigned to sibutramine $15 \mathrm{mg}$ /day $(n=30)$ or placebo $(n=30)$ for 12 weeks at two centers. ${ }^{105}$ Compared with placebo, sibutramine was associated with a significant reduction in number of binge days, greater weight loss, and significantly greater decreases in Binge Eating Scale and Beck Depression Inventory scores. Seven (23\%) sibutramine patients and five (17\%) placebo patients did not complete the trial. Dry mouth and constipation were more common with sibutramine than placebo. In the second study, 20 women with BED by DSM-IV criteria and obesity were randomized to receive sibutramine $10 \mathrm{mg} /$ day $(\mathrm{n}=10)$ or placebo $(n=10)$ for 12 weeks. ${ }^{106}$ At study end, average binge day frequency was significantly decreased among women receiving sibutramine (from $4.4 \pm 1.0$ to $1.0 \pm 1.0$; $P<0.001)$ but unchanged among those receiving placebo (from $4.7 \pm 1.3$ to $4.4 \pm 0.5$ ). Similarly, Body-Esteem Scale ${ }^{107}$ scores improved significantly among sibutramine-treated patients but not among those given placebo. The average weight loss among sibutramine recipients $(4.5 \pm 2.1 \mathrm{~kg})$ was significantly $(P<0.001)$ greater than that among placebo recipients $(0.6 \pm 05 \mathrm{~kg})$. The most common adverse events with sibutramine were dry mouth and constipation.

The third study was a multisite trial in which 304 participants with DSM-IV BED were randomized to sibutramine $(15 \mathrm{mg} /$ day; $\mathrm{n}=152)$ or placebo $(\mathrm{n}=152)$ for 24 weeks at 18 centers. All patients received dietary/life style psychoeducation. Compared with placebo-treated patients, sibutraminetreated patients had significantly greater reductions in weekly binge frequency (sibutramine group mean $2.7 \%$, placebo group mean $2.0 \%$ ), binge day frequency, weight, BMI, and measures of cognitive restraint, disinhibition, and hunger as assessed by the Three Factor Eating Questionnaire (TFEQ). Sibutramine-treated patients also showed significantly greater global improvement and level of response, including remission of binge eating (59\% for sibutramine versus $43 \%$ for placebo). More sibutramine recipients (67\%) than placebo recipients (57\%) completed the study. Headache, dry mouth, constipation, insomnia, and dizziness were significantly more common with sibutramine.

\section{Orlistat}

Orlistat is a gastrointestinal lipase inhibitor indicated for weight loss and weight maintenance. ${ }^{103}$ Its mechanism of action is inhibition of absorption of dietary fat. Two randomized, placebo-controlled studies have been conducted with orlistat in BED. In one study, 50 patients with BED by DSM-IV criteria and obesity were randomized to receive individual CBT delivered by guided self-help (CBTgsh) in combination with orlistat $120 \mathrm{mg}$ three times daily or CBTgsh in combination with placebo for 12 weeks. ${ }^{87} \mathrm{At}$ the 12-week time point, both CBTgsh and study medication were discontinued and the double-blind for medication was broken. Patients were again evaluated at 3-month follow-up. There were two primary outcomes, ie, remission of binge eating, defined as no binge eating episodes in the past month, and weight loss, defined as losing at least 5\% of weight from baseline. Binge eating remission rates were significantly higher for orlistat plus CBTgsh than for placebo plush CBTgsh at post-treatment ( $64 \%$ versus $36 \%$ ) but not at 3-month follow-up (52\% in both groups). However, rates for achieving at least $5 \%$ weight loss were significantly higher for the orlistat group at both post-treatment (36\% versus $8 \%$ ) and 3-month follow-up (32\% versus $8 \%$ ).

In the second study, 89 patients with BED by DSM-IV criteria and obesity were randomized to orlistat $120 \mathrm{mg}$ three times daily $(n=44)$ or placebo $(n=45)$ for 24 weeks, both in combination with a mildly hypocaloric diet. ${ }^{108}$ Mean percentage weight loss (the primary outcome) was significantly greater for orlistat-treated patients than for placebotreated patients $(-7.4 \%$ versus $-2.3 \% ; P=0.0001)$. Waist circumference, hip circumference, total percentage body fat, total cholesterol level, diastolic blood pressure, and insulin level were also significantly improved with orlistat. Effectiveness of orlistat in binge eating per se was less clear. At 24 weeks, the mean number of binge eating episodes per week was numerically but not significantly decreased (1.0 for orlistat-treated patients versus 1.7 for placebo-treated patients). Also, similar rates of patients in both groups who completed the study continued to suffer from BED (23\% for orlistat versus 29\% for placebo). However, Eating Disorder Inventory scores at week 24 were significantly lower for orlistat than placebo $(P=0.011)$. In addition, fat intake was significantly lower in orlistat-treated patients at week 12; total caloric intake was significantly lower at week 24. Eighteen patients discontinued the study prematurely, five (11\%) in the orlistat group and 13 (29\%) in the placebo group. No patient discontinued orlistat because of an adverse event. Data on side effects were otherwise not reported.

These studies are noteworthy because they suggest that a drug with no direct action on the central nervous system (the bioavailability of orlistat is $<1 \%$ ) may have beneficial 
effects in BED. ${ }^{103}$ Of note, orlistat misuse has been reported in patients with eating disorders, including those with bulimia nervosa $^{97,109}$ and BED. ${ }^{110}$

\section{Other antiobesity agents}

Phentermine is the most commonly prescribed medication for obesity in the US, and is approved for short-term use. ${ }^{63}$ It is a sympathomimetic amine that is thought to suppress appetite by promoting norepinephrine release. ${ }^{111}$ Side effect concerns include elevation of pulse and blood pressure. Phentermine is currently under evaluation as a component in combination with topiramate and with pramlintide for weight loss in obesity. ${ }^{63,112,113}$

There are no reports of phentermine monotherapy in BED, but two open-label trials evaluated the drug in combination with other treatments. In a six-month study, administration of phentermine $15 \mathrm{mg}$ /day plus fenfluramine $60 \mathrm{mg}$ /day, to 22 severe binge eaters, 17 moderate binge eaters, and 16 nonbinge eaters, resulted in improved binge eating and Beck Depression Inventory scores in all three groups. ${ }^{114}$ In addition, $73 \%$ of the severe binge eaters, $59 \%$ of the moderate binge eaters, and $69 \%$ of the nonbinge eaters experienced more than $10 \%$ weight loss. However, of 35 patients who received echocardiograms, 20 had evidence of valvular insufficiency in one or more valves. In the second study, phentermine up to $30 \mathrm{mg} /$ day, in combination with fluoxetine up to $60 \mathrm{mg} / \mathrm{day}$, and CBT was assessed in 16 obese women with binge eating, 14 of whom met DSM-IV criteria for BED. ${ }^{115}$ During the 20 -week active treatment phase, mean weekly binge frequency declined by $95 \%$ from baseline, with 12 (75\%) patients showing complete remission. Mean body weight and BMI declined by $8.6 \%$ and $8.7 \%$, respectively, from baseline. After 6 months of subsequent maintenance treatment, 12 patients remained on study medication (10 patients on both agents and two patients on fluoxetine alone); binge frequency was $63 \%$ lower than at the start of treatment, but only five (42\%) of the 12 patients were binge-free. Only six patients completed 18 months of maintenance therapy; two were taking both medications and four were taking fluoxetine alone. Four of five BED patients were in remission from binge eating, but patients had regained most of the weight they had lost at the end of active treatment.

\section{Antiepileptic drugs}

Several rationales have prompted studies of antiepileptic drugs in BED. First is that early investigators noted that some patients with binge eating episodes and electrocardiographic abnormalities stopped binge eating when treated with phenytoin. ${ }^{116-119}$ Second is that BED co-occurs with a number of conditions that respond to various antiepileptic agents, including mood, alcohol use, and borderline personality disorders. ${ }^{120}$ Third is that some antiepileptic drugs are associated with weight loss and/or anorexia, ${ }^{50}$ and have been shown to be efficacious as weight loss agents in obesity, either as monotherapy (eg, topiramate and zonisamide) $)^{121,122}$ or as components of combination therapies (eg, topiramate with phentermine, and zonisamide with bupropion). ${ }^{63,113}$ Fourth is that a number antiepileptic drugs affect neurotransmitter or peptide systems involved in regulation of feeding behavior. As noted earlier, topiramate affects the glutamate and neuropeptide $Y$ systems, while zonisamide affects neuropeptide $Y$ and enhances serotonin and dopamine function. ${ }^{53,56,57}$ The antiepileptic drugs studied thus far in BED in randomized, controlled trials include topiramate, zonisamide, and lamotrigine. Phenytoin has been studied in the similar condition compulsive or binge eating. ${ }^{122}$

\section{Topiramate}

Topiramate is a sulfamate-substituted monosaccharide that is approved for epilepsy and migraine. It has multiple pharmacological properties, including antagonism of the AMPA/ kainate glutamate receptor, state-dependent blockade of voltage-activated sodium channels, enhancement of gammaaminobutyric acid (GABA) activity at the GABA receptor, antagonism of high voltage-activated calcium channels, and inhibition of carbonic anhydrase..$^{55,123,124}$ In randomized placebo-controlled trials in obese individuals without BED, topiramate monotherapy produces weight loss of about $6-8 \mathrm{~kg}$ at 24 weeks with improvements in lipid parameters, glycemic control, and blood pressure. ${ }^{125-127}$ A large program sponsored by Vivus exploring the combination of low-dose controlled-release topiramate with phentermine (at both $46 / 7.5 \mathrm{mg} /$ day and 92/15 mg/day) in obesity has shown that this combination is efficacious and well tolerated for acute weight loss and long-term weight maintenance. ${ }^{128-130}$ Moreover, this combination was associated with improved cardiovascular and metabolic variables and a decreased rate of incident diabetes.

Three randomized, placebo-controlled trials of topiramate have been published to date in BED. In the first study, $61 \mathrm{BED}$ patients with obesity received topiramate $(n=30)$ or placebo $(\mathrm{n}=31)$ for 14 weeks. ${ }^{83}$ Topiramate was started at $50 \mathrm{mg} /$ day and could be increased to a maximum of $600 \mathrm{mg} /$ day according to response and tolerability. Topiramate (median dose $212 \mathrm{mg} /$ day) was significantly superior to placebo in 
reducing binge frequency, as well as obsessive-compulsive features of binge eating symptoms, as assessed with the Yale-Brown Obsessive Compulsive Scale Modified for Binge Eating (YBOCS-BE), global severity of illness, body weight, and BMI. Topiramate-treated patients experienced a $94 \%$ reduction in binge frequency and a mean weight loss of $5.9 \mathrm{~kg}$, whereas placebo-treated patients experienced a $46 \%$ reduction in binge frequency and a mean weight loss of $1.2 \mathrm{~kg}$. However, the dropout rate was high, with 14 (47\%) topiramate recipients and $12(39 \%)$ placebo recipients failing to complete the trial. Paresthesias, dry mouth, headache, and dyspepsia were the most common side effects associated with topiramate.

The second controlled study was a multicenter trial in which 407 patients with BED and at least three binge eating days/week, BMI 30-52 kg/m², and no current psychiatric disorders or substance abuse were randomized to receive topiramate or placebo for 16 weeks. ${ }^{61}$ Topiramate was started at $25 \mathrm{mg} /$ day and increased over an 8-week period to $400 \mathrm{mg} /$ day or the maximum tolerated dose; the median final dose was $300 \mathrm{mg} /$ day. Thirteen enrolled patients failed to meet the inclusion criteria, resulting in 195 topiramate and 199 placebo patients who were evaluated for efficacy. Compared with placebo, topiramate significantly reduced weekly binge day frequency $(-3.5 \pm 1.9$ versus $-2.5 \pm 2.1)$, binge frequency $(-5.0 \pm 4.3$ versus $-3.4 \pm 3.8)$, weight $(-4.5 \pm 5.1 \mathrm{~kg}$ versus $0.2 \pm 3.2 \mathrm{~kg})$, and BMI $\left(-1.6 \pm 1.8 \mathrm{~kg} / \mathrm{m}^{2}\right.$ versus $0.1 \pm 1.2 \mathrm{~kg} / \mathrm{m}^{2}$, all $\left.P<0.001\right)$. Topiramate also significantly decreased obsession, compulsion, and total scores of the YBOCS-BE; overall, motor, and nonplanning impulsiveness scores of the Barratt Impulsiveness Scale, version $11 ;^{131}$ cognitive restraint, disinhibition, and hunger subscores of the TFEQ; and overall, social, and family life disability scores of the Sheehan Disability Scale. Significantly more topiramate-treated subjects (58\%) achieved remission compared with placebo-treated subjects $(29 \%$; $P<0.001)$. Discontinuation rates were $30 \%$ in each group; adverse events were the most common reason for topiramate discontinuation (16\% versus $8 \%$ for placebo). Paresthesias, upper respiratory tract infection, somnolence, and nausea were the most frequent side effects of topiramate.

The third controlled study of topiramate in BED was another multicenter trial in which 73 patients with BED and obesity were randomized to 19 sessions of CBT in conjunction with topiramate $(n=37)$ or placebo $(n=36)$ for 21 weeks. ${ }^{132}$ The final mean dose of topiramate was $206 \pm 36 \mathrm{mg} /$ day. Both treatment groups showed significant reductions in binge frequency. However, compared with patients receiving placebo, those receiving topiramate showed a significantly greater rate of weight reduction (the primary outcome measure) over the course of treatment $(P<0.001)$. Topiramate recipients also showed significantly greater mean weight loss $(-6.8 \mathrm{~kg})$ compared with placebo recipients $(-0.9 \mathrm{~kg})$. Reduction of binge frequencies and Binge Eating Scale and Beck Depression Inventory scores did not differ between the groups, but a greater proportion of topiramate-treated patients $(84 \%)$ attained remission of binge eating as compared with placebo-treated patients $(61 \%$; $P=0.03)$. There was no difference between the groups with regard to completion rates. Paresthesias and taste perversion were more frequent with topiramate, whereas insomnia was more frequent with placebo. The authors concluded that adding topiramate to CBT improved the efficacy of the latter for BED, enhancing both weight loss and binge remission over the short term. ${ }^{132}$

There have been no randomized, placebo-controlled maintenance studies of antiepileptic drugs in BED. An openlabel extension trial suggested that the antibinge eating and weight loss effects of topiramate may be maintained over the long term. BED patients who completed the first randomized, placebo-controlled study of topiramate $(n=35)$ were offered participation in a 42-week open-label extension study of the drug. ${ }^{133}$ An analysis was conducted for 44 patients who received at least one dose of topiramate (31 who received topiramate in the open-label trial plus 13 who received topiramate in the double-blind study only); 43 patients provided outcome measures at a final median dose of $250 \mathrm{mg} /$ day. Mean weekly binge frequency declined significantly from baseline to the final visit for all 43 patients $(-3.2 ; P<0.001)$, for the 15 patients who received topiramate during the controlled and open-label studies $(-4.0 ; P<0.001)$, and for the 15 patients who received topiramate only during the open-label trial $(-2.5 ; P=0.044)$. Patients also exhibited a statistically significant reduction in body weight. However, only $10(32 \%)$ of the 31 patients entering the extension trial completed the 42 weeks of open-label treatment, with the most common reasons for topiramate discontinuation being protocol nonadherence $(n=11)$ and adverse events $(n=8)$.

There are notable open-label descriptions of the beneficial use of topiramate in difficult-to-treat patients with BED. Thus, topiramate has been reported to reduce binge eating and/or overweight in BED patients with treatment-resistant illness, comorbid depressive or bipolar disorders, traumatic brain injury, and those receiving the drug adjunctively with antidepressants and/or mood stabilizers. ${ }^{134-138}$ Topiramate has also been used successfully to reduce binge eating and weight 
loss difficulties after adjustable gastric banding or gastric bypass surgery. ${ }^{139,140} \mathrm{On}$ the other hand, there are reports of topiramate misuse in eating disorder patients. ${ }^{141}$

\section{Zonisamide}

Zonisamide is a second-generation antiepileptic drug with broad-spectrum efficacy. It has many pharmacologic properties, including antagonism of voltage-gated sodium and T-type calcium channels, reduction of glutamate transmission by blockade of potassium-evoked glutamate release and upregulation of excitatory amino acid carrier-1, modulation of central dopaminergic and serotonergic function, and carbonic anhydrase inhibition. ${ }^{53,142}$ A large program sponsored by Orexigen Therapeutics evaluating zonisamide in combination with bupropion in obesity has shown that the combination is associated with more weight loss than either drug alone. ${ }^{143,144}$

One randomized controlled study of zonisamide has been published in BED. ${ }^{142}$ In that study, 60 patients with DSM-IV BED and obesity received flexible-dose (100-600 mg/day) zonisamide monotherapy $(n=30)$ or placebo $(n=30)$ for 16 weeks. The mean zonisamide daily dose at endpoint was $436 \pm 159 \mathrm{mg} /$ day. Compared with placebo, zonisamide was associated with a significantly greater rate of reduction in binge frequency $(P=0.021)$, body weight $(P<0.0001)$, BMI $(P=0.0001)$, and scores on the Clinical Global Impression-Severity $(P<0.0001)$, YBOCS-BE $(P<0.0001)$, and TFEQ disinhibition $(P<0.0001)$ scales. Plasma ghrelin concentrations increased with zonisamide but decreased with placebo $(P=0.0001)$. However, the attrition rate was high, with $18(60 \%)$ zonisamide-treated patients and $12(40 \%)$ placebo-treated patients failing to complete the 12-week treatment period. Eight zonisamide recipients discontinued for adverse events. The most common reasons for stopping zonisamide were cognitive complaints $(n=2)$, psychological complaints $(n=2)$, and bone fracture $(n=2)$. The most common side effects associated with zonisamide were dry mouth, somnolence, headache, nausea, nervousness, and altered taste. This trial was consistent with an earlier open-label study in which zonisamide was associated with reduced binge eating and body weight but also with a high discontinuation rate. ${ }^{145}$

\section{Lamotrigine}

Lamotrigine is a broad-spectrum antiepileptic agent with regulatory approval for maintenance treatment of bipolar disorder in many countries. Pharmacodynamic actions include reduction of presynaptic glutamate release..$^{55,123}$ The drug has been evaluated in one randomized, placebo-controlled trial in 51 patients with BED and obesity. ${ }^{146}$ Because lamotrigine and placebo had similarly high rates of reduction of weekly frequency of binge-eating episodes, the efficacy of lamotrigine in BED could not be determined. However, lamotrigine was associated with a numerically greater amount of weight loss $(1.17 \mathrm{~kg}$ for lamotrigine versus $0.15 \mathrm{~kg}$ for placebo) and statistically significant reductions in fasting levels of glucose, insulin, and triglycerides, consistent with the finding that lamotrigine is associated with weight loss in healthy patients with obesity. ${ }^{147}$

\section{Phenytoin}

Two published placebo-controlled crossover studies of phenytoin in patients with compulsive or binge eating had contrasting results. ${ }^{117}$ In the negative trial, four obese patients with compulsive eating showed no significant differences between phenytoin and placebo on any outcome measure. ${ }^{148}$ In addition, no patient had a marked response to phenytoin. In the positive study, 19 of 20 women with "binge eating syndrome" completed 12 weeks during which they received phenytoin and placebo for six weeks each in a counterbalanced design. ${ }^{149}$ Twelve patients had final serum phenytoin levels of $10-20 \mu / \mathrm{mL}$, and five had levels of $5-10 \mu / \mathrm{mL}$. Patients given phenytoin first experienced a $37 \%$ decrease in binge frequency $(P<0.01)$, but showed no change in binge frequency when switched to placebo. Patients given placebo first experienced no change in binge frequency, and did experience a $39 \%$ decrease after switching to phenytoin $(P<0.01)$. Eight $(42 \%)$ patients displayed a moderate or better response $(\geq 50 \%$ reduction in binge episode frequency) on phenytoin, but only one patient experienced a remission of binge eating. When the two groups were compared, there were significantly fewer binges in the phenytoin-placebo group than in the placebophenytoin group $(P<0.02)$, indicating a carryover effect for the phenytoin-first sequence.

\section{Other antiepileptics}

A case series of nine obese patients with BED treated with oxcarbazepine had inconsistent findings. ${ }^{150}$ Four patients showed a decrease in binge eating and three lost weight. However, three patients reported no change in binge eating, two showed no weight change, and five gained weight. Five patients discontinued the drug and seven reported side effects. The authors noted that the drug appeared to be beneficial for patients with impulsive eating behaviors and depressive symptoms. In contrast, valproate has been reported to worsen 
binge eating and enhance weight gain in patients with BED and comorbid bipolar disorder. ${ }^{138}$

\section{Drugs for attention deficit hyperactivity disorder}

Several rationales have prompted studies of attention deficit hyperactivity disorder medications in BED. First is that most drugs used to treat attention deficit hyperactivity disorder facilitate function of the dopamine and/or norepinephrine systems, which are involved in eating behavior and reward as well as in the biology of binge eating. ${ }^{37,74,151}$ Second, many drugs used to treat attention deficit hyperactivity disorder are associated with weight loss or anorectic effects, and there are preliminary reports that stimulants such as methylamphetamine and methylphenidate reduce binge eating in patients with bulimia nervosa. ${ }^{152-156}$ Third, epidemiological data have indicated a relationship between BED and attention deficit hyperactivity disorder in both adolescents ${ }^{28}$ and adults. ${ }^{3}$ These observations have led to studies of atomoxetine, methylphenidate, and lisdexamfetamine in BED.

\section{Norepinephrine reuptake inhibitors}

Atomoxetine is a highly selective norepinephrine reuptake inhibitor approved by the US Food and Drug Administration for the treatment of attention deficit hyperactivity disorder. In the only controlled study of atomoxetine in BED, 40 patients were randomized to receive the active drug or placebo for 10 weeks at a single center. ${ }^{61}$ Atomoxetine was flexibly dosed at 40-120 mg/day; the mean dose at endpoint evaluation was $106 \pm 21 \mathrm{mg} /$ day. Compared with placebo-treated patients $(n=20)$, atomoxetine-treated patients $(n=20)$ showed a significantly greater decrease in binge frequency (the primary outcome measure), as well as in binge day frequency, weight, BMI, and scores on the Clinical Global Impression-Severity scale, YBOCS-BE obsession subscale, and TFEQ hunger subscale. Fifteen patients (six receiving atomoxetine) did not complete the 10 -week trial. The most common side effects associated with atomoxetine were dry mouth, nausea, nervousness, insomnia, headache, constipation, and sweating. The only other selective norepinephrine reuptake inhibitor studied in BED has been reboxetine. In a 12-week open-label trial in nine patients, significant reductions were seen in binge frequency and BMI. ${ }^{157}$

\section{Stimulants}

A double-blind, placebo-controlled crossover study in 32 patients with BED and 46 healthy age-matched controls showed that BED patients with at least one copy of the nine-repeat allele of the dopamine transporter showed significant appetite suppression in response to methylphenidate compared with controls with this allele or BED patients with the 10/10 genotype, whose methylphenidate response was indistinguishable from placebo. ${ }^{158}$ The authors hypothesized that a currently unknown genetic variant, which is overrepresented in BED, interacts with the dopamine transporter to suppress appetite in response to stimulant administration.

Lisdexamfetamine is a prodrug of d-amphetamine marketed for the treatment of attention deficit hyperactivity disorder in children and adults. Amphetamine inhibits the reuptake and enhances the release of dopamine and norepinephrine. ${ }^{111}$ Two randomized, placebo-controlled trials of this compound are presently ongoing in patients with BED by DSM-IV criteria (NCT01090713 and NCT01291173; retrieved April 25, 2012). ${ }^{1}$

\section{Antiaddiction drugs}

The pharmacotherapy of addictive disorders has gained considerable empirical support, such that a class of "anticraving" drugs has been hypothesized to exist that reduces cravings or urges to use alcohol or drugs of abuse. ${ }^{159}$ Growing research suggests addictive processes, including addiction to highly palatable food, are involved in the development and maintenance of obesity. ${ }^{160}$ Eating disorders with binge eating, including BED, also appear to be related to addictive disorders, though their precise relationships to food addiction per se have not been fully elucidated. ${ }^{161}$ Thus, the binge eating of BED is characterized by craving for food and loss of control over eating that are similar to the craving for alcohol and drugs and loss of control over the use of these substances that is seen in persons with addiction. Additionally, BED is associated with elevated rates of substance use disorders. ${ }^{3,28}$ These observations have led to the hypothesis that binge eating and addiction may share a common pathophysiology involving highly palatable food and drugs of abuse competing for the same brain reward circuitry, and that anticraving drugs may reduce the urge to binge by modulating neurotransmission in the systems that comprise this circuitry. ${ }^{162}$

\section{Opioid antagonists}

Involvement of the endogenous opioid system in eating behavior, reward, and addiction has prompted a number of studies of opioid antagonists in the treatment of binge-eating populations. Though placebo-controlled trials of naltrexone at standard doses in bulimia nervosa have largely been negative, ${ }^{75,163}$ other studies in bulimia nervosa and open reports in BED have suggested that supratherapeutic doses (200-400 mg/day) may decrease binge eating. ${ }^{164-166}$ In a study of 41 women, 
intravenous administration of the opioid antagonist, naloxone, selectively suppressed the consumption of sweet high-fat foods in obese and lean subjects with bulimia nervosa $(n=20)$, but not in controls $(n=21) .{ }^{167}$ Moreover, a large program sponsored by Orexigen Therapeutics evaluating naltrexone in combination with bupropion in obesity has shown that the combination is associated with more weight loss than either drug alone. ${ }^{168-170}$

In the only randomized controlled trial of naltrexone to include patients with BED, 33 obese bingers and 22 normal weight bulimics were treated for 8 weeks with naltrexone 100-150 mg/day, imipramine, or placebo. ${ }^{75}$ Naltrexone did not significantly reduce binge duration or binge frequency in the obese bingers. However, three favorable case reports of naltrexone in BED have been published. One was a positive on-off-on case of naltrexone monotherapy using doses of 200 and $400 \mathrm{mg} /$ day. ${ }^{171}$ The two others described the successful augmentation of fluoxetine using naltrexone $100 \mathrm{mg} /$ day. ${ }^{172,173}$ There are also reports of opioid antagonists being helpful in BED patients with serious comorbid neuropsychiatric and medical disorders. ${ }^{166}$

ALKS-33 is a novel compound in clinical development by Alkermes for alcohol dependence that binds nonselectively to $\mu, \kappa$, and $\delta$ opioid receptors. ${ }^{174}$ Unlike naltrexone, it does not undergo extensive first-pass metabolism and exhibits high oral bioavailability. A randomized, double-blind, placebocontrolled, 6-week study designed to assess the safety and efficacy of ALKS $3310 \mathrm{mg}$ /day in 68 patients with BED was recently completed. While ALKS 33 demonstrated a significant reduction from baseline in the efficacy endpoint of self-reported weekly binge eating episodes, the reduction was not significantly different from that observed with placebo. ${ }^{175}$

\section{Acamprosate}

Acamprosate is a glutamate receptor modulator approved in many countries for maintenance of abstinence in patients with alcohol dependence. The drug antagonizes the glutamate N-methyl-D-aspartate receptor and may also decrease mGluR5 function. ${ }^{123,176}$ In addition to the overlap between BED and addictive disorders, preclinical and clinical findings suggesting that reduction of glutamate function may decrease feeding behavior, including binge eating, prompted one randomized, placebo-controlled trial in BED. ${ }^{162}$ Forty patients with BED received acamprosate $(n=20)$ or placebo $(n=20)$ for 10 weeks. The mean endpoint daily dose of acamprosate was $2597 \pm 605 \mathrm{mg} /$ day. Acamprosate was not associated with a significantly greater decrease in binge frequency or any other outcome measure in the primary longitudinal analysis. However, in the secondary endpoint analysis, acamprosate was associated with statistically significant improvement in binge day frequency and in measures of obsessivecompulsive symptoms of binge eating, food craving, and quality of life. BMI decreased slightly with acamprosate and increased with placebo; among completers, BMI decreased significantly more for acamprosate recipients than placebo recipients $(P=0.04)$. In addition, the drug was well tolerated, with a significantly higher completion $(79 \%)$ rate than for placebo $(45 \%, P=0.05)$. Consistent with its adverse event profile in alcohol-dependent patients, diarrhea was the more common side effect. There were no serious adverse events.

\section{Other agents}

Memantine, a glutamate-modulating agent, has been reported to reduce binge eating in BED in two open-label trials. In the first trial, five women with BED and obesity received memantine $10 \mathrm{mg}$ in the morning and $10-20 \mathrm{mg}$ in the late afternoon. As a group, they also lost weight, on average, $1.2 \mathrm{~kg}$ per week. ${ }^{177}$ In the second, 16 patients received a mean endpoint memantine dose of $18.3 \mathrm{mg} /$ day. Although they did not lose weight as a group, weight loss was seen in four patients who had a remission of binge eating. ${ }^{178}$

Sodium oxybate, the sodium salt of gamma-hydroxybutyrate, is a Schedule III drug marketed for the treatment of excessive daytime sleepiness and cataplexy in patients with narcolepsy. ${ }^{179}$ Present in human brain as a metabolite of GABA, and with at least two identified receptors, gammahydroxybutyrate modulates a number of neurotransmitters involved in the regulation of feeding behavior, including GABA, dopamine, serotonin, opioids, and glutamate. ${ }^{180}$ Findings that chronic gamma-hydroxybutyrate and gammahydroxybutyrate analogs decrease aspects of excess feeding behavior, the anticraving properties of the drug, and evidence of a link between narcolepsy and binge eating prompted an open-label 16-week study of the drug in 12 patients with BED. ${ }^{181,182}$ Ten patients completed at least one post-baseline evaluation, and five completed the study. The mean endpoint dose was $7.1 \pm 2.0 \mathrm{~g} /$ day. Sodium oxybate was associated with significant reductions in binge day and binge episode frequencies, as well as measures of clinical severity, eating pathology, obsessive-compulsive symptoms, food cravings, BMI, and body weight. Nine participants had remission of binge eating and five lost $\geq 5 \%$ of their baseline weight; all five of the latter participants had remission of binge eating.

Baclofen, a GABA(B) agonist, given at $60 \mathrm{mg} /$ day for 10 weeks has also been reported to reduce binge eating 
Table 5 Examples of novel pharmacotherapies under investigation for obesity

\begin{tabular}{|c|c|}
\hline Agent & $\begin{array}{l}\text { Putative mechanism of action } \\
\text { for weight loss }\end{array}$ \\
\hline \multicolumn{2}{|l|}{ Monotherapies } \\
\hline Lorcaserin & Selective $5-\mathrm{HT}_{2 \mathrm{C}}$ receptor agonism \\
\hline Tesofensine & $\begin{array}{l}\text { Reuptake inhibition of NE, DA, } \\
\text { and } 5 \mathrm{HT}\end{array}$ \\
\hline Pramlintide, davalintide & Amylin agonism \\
\hline Exenatide, liraglutide & Glucagon-like peptide-I agonism \\
\hline Velneperit & $\begin{array}{l}\text { Neuropeptide Y Y5 receptor } \\
\text { antagonism }\end{array}$ \\
\hline \multicolumn{2}{|l|}{ Combination Therapies } \\
\hline Bupropion plus naltrexone & Sustained increase in $\alpha-\mathrm{MSH}$ release \\
\hline Bupropion plus zonisamide & $\begin{array}{l}\text { Enhancement of central NE, DA, } \\
\text { and } 5 \mathrm{HT} \text { function }\end{array}$ \\
\hline Topiramate plus phentermine & $\begin{array}{l}\text { Glutamate antagonism and increased } \\
\text { central NE release }\end{array}$ \\
\hline Pramlintide plus metreleptin & Combined amylin and leptin agonism \\
\hline Pramlintide plus phentermine & $\begin{array}{l}\text { Amylin agonism and increased } \\
\text { central NE release }\end{array}$ \\
\hline
\end{tabular}

Abbreviations: DA, dopamine; $5 \mathrm{HT}$, serotonin; $\alpha-M S H, \alpha$-melanocyte stimulating hormone; NE, norepinephrine.

frequency in BED; however, in this study, two of four women with BED gained weight at the trial endpoint despite reporting reduced binge eating. ${ }^{183}$

There are no published controlled studies of antipsychotics in BED. Rather, second-generation antipsychotics have been reported to induce or exacerbate binge eating in patients with binge eating-related disorders, including bulimia nervosa. ${ }^{184,185}$ Moreover, second-generation antipsychotics have been reported to induce or exacerbate binge eating, including syndromal BED, in patients receiving the drugs for psychotic disorders. ${ }^{186}$

\section{Conclusion}

Research into the pharmacotherapeutic treatment of BED is in its early stages. No single medication has received approval from a regulatory body for use in BED. Many of the available pharmacotherapy studies in BED are plagued by limitations, such as small sample size, a high placebo response, high dropout rates, and unclear generalizability of findings to real world clinical situations. ${ }^{187}$ No placebocontrolled maintenance trial in a group of patients whose binge eating was in remission has yet been published. There have been no placebo-controlled pharmacotherapy studies devoted to BED patients who have had partial or inadequate responses to pharmacotherapy, psychotherapy, or bariatric surgery. Also, there have been no pharmacotherapy studies in children, adolescents, or older adults with BED. Moreover, except for obesity and major depressive disorder, there has been no pharmacotherapy study of patients with BED and a specified psychiatric or medical comorbidity.

However, many individuals with BED receive pharmacotherapy, ${ }^{11,188}$ and several conclusions regarding the pharmacotherapy of BED from extant research can nonetheless be made. Substantial evidence indicates that antidepressants are modestly efficacious for binge eating in BED over the short term. ${ }^{21,89}$ Antidepressants, including the serotonin-norepinephrine reuptake inhibitor, duloxetine, may also be useful for the depressive symptoms and/or syndromes that may accompany BED. However, they do not appear to have clinically significant benefits on body weight, and their long-term efficacy in BED is not known. Nor do they appear to enhance the antibinge eating effects of CBT significantly. However, it is unknown whether these findings would generalize to other available antidepressants with different pharmacodynamic profiles, such as bupropion or vilazodone.

Considerable double-blind, placebo-controlled data show that topiramate is effective for binge eating in BED with obesity. These data also show that topiramate is effective for weight loss in this patient population and decreases both obsessive-compulsive eating pathology as well as features of trait impulsivity. ${ }^{61}$ One controlled study showed topiramate may enhance the effectiveness of CBT in BED, ${ }^{132}$ while an open-label study found the antibinge eating and weight loss effects of topiramate in BED may persist for up to one year (though drug discontinuation rates were high, in part due to adverse events). ${ }^{133} \mathrm{~A}$ comparable amount of controlled data show that sibutramine is effective for reduction of binge eating and weight loss in BED with obesity, ${ }^{62}$ but this drug is no longer available because of safety concerns. Orlistat, when used in combination with CBT or dietary therapy, leads to enhanced weight loss and possibly reduced binge eating. ${ }^{77,108}$ Other compounds that are presently available and that show promise for BED are zonisamide, naltrexone (especially at doses higher than those used for substance use disorders), stimulants, and glutamate-modulating agents (eg, memantine). These compounds merit more systematic evaluation in BED.

Further pharmacotherapy research into BED is greatly needed at many levels. Randomized, placebo-controlled maintenance trials would be useful for antidepressants, topiramate, and orlistat in BED. Randomized control trials in which a novel medication strategy (eg, topiramate maintenance treatment of BED) is combined with a specific psychological treatment would be useful. As has been done in other major mental disorders, trials are needed to explore strategies 
where medications are optimized, switched, augmented, or combined in patients with treatment-resistant BED. ${ }^{189}$ For example, studies of topiramate in combination with antidepressants would be important in patients with inadequately responsive or chronic forms of BED, including those with comorbid depressive disorders. ${ }^{190}$ In addition, studies are needed in BED patients who have clinically important comorbidities beyond obesity and depression, such as bipolar disorder, anxiety disorders, substance use disorders, diabetes, hypertension, dyslipidemia, and metabolic syndrome. ${ }^{3,7}$ For example, in epidemiologic samples, it has been estimated that $12 \%$ of individuals with BED have bipolar disorder, $65 \%$ have an anxiety disorder, and $23 \%$ have a substance use disorder; ${ }^{3}$ while over 5 -year prospective follow-up, $10 \%$ will develop diabetes, $24 \%$ hypertension, and $30 \%$ dyslipidemia. ${ }^{?}$

Studies with new compounds are also greatly needed in BED. Available drugs that may hold promise for BED and merit evaluation in randomized controlled trials include the serotonin-norepinephrine reuptake inhibitors desvenlafaxine, venlafaxine, and milnacipran; bupropion; the combined SSRI-5HT $\mathrm{HA}_{1 \mathrm{~A}}$ agonist vilazodone; memantine and other glutamate-modulating agents, such as riluzole ${ }^{64,191}$ and long-acting stimulant preparations, such as OROS-methylphenidate. Novel compounds that hold promise for BED include some of those in development for obesity (Table 5) and mood disorders. Examples of such compounds being developed for obesity include tesofensine, a serotonin-norepinephrinedopamine (triple) reuptake inhibitor; selective $5-\mathrm{HT}_{2 \mathrm{C}}$ receptor agonists (eg, lorcaserin); melanin-concentrating hormone receptor 1 antagonists; combination therapies (eg, bupropion sustained-release with naltrexone sustained-release, bupropion with zonisamide, and topiramate with phentermine); and agents that target hormones and peptides that control appetite or regulate metabolism. ${ }^{60,65,192-198}$ Examples of such agents being developed for depression include triple reuptake inhibitors, serotonin-melatonin agents, and corticotropin-releasing hormone antagonists. ${ }^{64,191,199}$ Drugs with potential for efficacy in both depression and obesity (eg, triple reuptake inhibitors), as well as combination therapies for obesity, might be especially promising candidates for BED. The former (eg, tesofensine and amitifadine) share mechanistic features with sibutramine, while the latter contain components (eg, topiramate and zonisamide) already shown effective in BED as monotherapy. Some of the many drugs in development for epilepsy might also be considered as potential therapeutic agents for BED, particularly if they are associated with anorectic or weight loss properties. ${ }^{67}$
Rational comprehensive guidelines for the use of pharmacotherapy in BED need to be developed. These guidelines will need to address the role of pharmacotherapy relative to other treatment modalities for BED, including psychological strategies and bariatric surgery, as well as the individual roles of different medications. Some authorities suggest psychotherapy should be the first-line treatment of BED and that current pharmacotherapies cannot be recommended because of insufficient evidence. ${ }^{10}$ However, this recommendation needs to account for patient preference, the incomplete effectiveness of psychotherapy, for the fact that pharmacotherapy can be combined with or added to all other BED treatments (both psychological and surgical), and for the potential lack of generalizability of the findings of psychotherapy studies. Moreover, BED is most likely to be a heterogeneous condition, and some patients may only respond optimally to pharmacotherapy, while others may respond to psychotherapy alone. ${ }^{200}$ Identification of factors predicting requirement of pharmacotherapy, along with the particular medications most likely to be effective, will help realize personalization of BED treatment.

Pharmacotherapy research for BED will need to be informed by advances in both clinical trial design, psychobiology, and molecular genetics. Regarding the former, there is presently a lack of consensus about what constitutes ideal clinical trial design in eating disorder pharmacotherapy research in general, and for BED in particular. This includes lack of agreement on assessment instruments, definitions of primary outcome and of response, remission, recovery, and relapse, stages of illness to be studied, metrics for reporting outcome, and how best to manage low completion rates. ${ }^{42,88}$ Regarding the latter, intensive research is needed to identify endophenotypes, genes, and other psychological or biological markers that will predict response to treatment and facilitate novel drug discovery. ${ }^{20,201}$

In summary, pharmacotherapy has an important role in the management of BED, especially in patients inadequately responsive to psychotherapy and surgery, patients with comorbid psychiatric or medical disorders, and those with chronic or intractable illness. However, the available pharmacotherapeutic armamentarium for BED and its supporting evidence base is far from adequate. Further study is needed to clarify which specific agents might be most useful for which patient subgroups, as well as to delineate the larger role of pharmacotherapy in relationship to other BED treatments. Novel medical treatments for BED are needed. In particular, rational drug discovery devoted to BED needs to occur. In the meantime, current and future medications with 
psychotropic benefits and/or favorable effects on appetite and weight might be considered as potential therapeutic agents for BED.

\section{Disclosure}

SL McElroy is a consultant to, or member of the scientific advisory boards, and/or a principal or co-investigator on research studies sponsored by Abbott Laboratories, Agency for Healthcare Research \& Quality (AHRQ), Alkermes, AstraZeneca, Bristol-Myers Squibb, Cephalon, Eli Lilly Inc., Forest Laboratories, GlaxoSmithKline, Jazz Pharmaceuticals, Marriott Foundation, National Institute of Mental Health (NIMH), Pfizer, Orexigen Therapeutics, Schering-Plough, Shire, Takeda Pharmaceutical Company, and Transcept Pharmaceutical, Inc. She is also inventor on United States Patent No. 6,323,236 B2, Use of Sulfamate Derivatives for Treating Impulse Control Disorders, and, along with the patient's assignee, University of Cincinnati, Cincinnati, Ohio, has received payments from Johnson \& Johnson Pharmaceutical Research \& Development, L.L.C., which has exclusive rights under the patent. All other authors report no conflicts of interest in this work.

\section{References}

1. American Psychiatric Association. Diagnostic and Statistical Manual of Mental Disorders, Fourth Edition, Text Revision. Washington, DC: American Psychiatric Association; 2000.

2. Wonderlich SA, Gordon KH, Mitchell JE, Crosby RD, Engel SG. The validity and clinical utility of binge eating disorder. Int $J$ Eat Disord. 2009;42(8):687-705.

3. Hudson JI, Hiripi E, Pope HG Jr, Kessler RC. The prevalence and correlates of eating disorders in the National Comorbidity Survey Replication. Biol Psychiatry. 2007;61(3):348-358.

4. Preti A, Girolamo G, Vilagut G, et al. The epidemiology of eating disorders in six European countries: results of the ESEMeD-WMH project. J Psychiatr Res. 2009;43(14):1125-1132.

5. Bulik CM, Reichborn-Kjennerud T. Medical morbidity in binge eating disorder. Int J Eat Disord. 2003;34 Suppl:S39-S46.

6. Hudson JI, Lalonde JK, Berry JM, et al. Binge-eating disorder as a distinct familial phenotype in obese individuals. Arch Gen Psychiatry. 2006;63(3):313-319.

7. Hudson JI, Lalonde JK, Coit CE, et al. Longitudinal study of the diagnosis of components of the metabolic syndrome in individuals with binge eating disorder. Am J Clin Nutr. 2010;91(6):1568-1573.

8. Javaras KN, Pope HG, Lalonde JK, et al. Co-occurrence of binge eating disorder with psychiatric and medical disorders. J Clin Psychiatry. 2008;69(2):266-273.

9. Pope HG Jr, Lalonde JK, Pindyck LJ, et al. Binge eating disorder: a stable syndrome. Am J Psychiatry. 2006;163(12):2181-2183.

10. Wilson GT. Treatment of binge eating disorder. Psychiatr Clin North Am. 2011;34(4):773-783.

11. Yager J. Binge eating disorder: The search for better treatments. Am J Psychiatry. 2008;165(1):4-6.

12. Hay PP, Bacaltchuk J, Stefano S, Kashyap P. Psychological treatments for bulimia nervosa and binging. Cochrane Database Syst Rev. 2009;4:CD000562.
13. Wadden TA, Faulconbridge LF, Jones-Corneille LR, et al. Binge eating disorder and the outcome of bariatric surgery at one year: a prospective, observational study. Obesity (Silver Spring). 2011;19(6):1220-1228.

14. Colles SL, Dixon JB, O’Brien PE. Grazing and loss of control related to eating: Two high-risk factors following bariatric surgery. Obesity (Silver Spring). 2008;16(3):615-622.

15. Kofman MD, Lent MR, Swencionis C. Maladaptive eating patterns, quality of life, and weight outcomes following gastric bypass: Results of an Internet survey. Obesity (Silver Spring). 2010;18(10):1938-1943.

16. Livhits M, Mercado C, Yermilov I, et al. Preoperative predictors of weight loss following bariatric surgery: systematic review. Obes Surg. 2012;22(1):70-89.

17. de Zwaan M, Hilbert A, Swan-Kremeier L, et al. Comprehensive interview assessment of eating behavior 18-35 months after gastric bypass surgery for morbid obesity. Surg Obes Relat Dis. 2010;6(1):79-85.

18. Berkman ND, Bulik CM, Brownley KA, et al. Management of eating disorders. Evid Rep Technol Assess (Full Rep). 2006;135:1-166.

19. Hudson JI, Carter WP, Pope HG Jr. Antidepressant treatment of binge-eating disorder: research findings and clinical guidelines. J Clin Psychiatry. 1996;57 Suppl 8:73-79.

20. Ramoz N, Versini A, Gorwood P. Eating disorders: an overview of treatment responses and the potential impact of vulnerability genes and endophenotypes. Expert Opin Pharmacother. 2007;8(13):2029-2044.

21. Reas DL, Grilo CM. Review and meta-analysis of pharmacotherapy for binge-eating disorder. Obesity (Silver Spring). 2008;16(9):2024-2038.

22. Steffen KJ, Roerig JL, Mitchell JE, Uppala S. Emerging drugs for eating disorder treatment. Expert Opin Emerg Drugs. 2006;11(2):315-336.

23. Yager J, Powers PS. Clinical Manual of Eating Disorders. Washington, DC: American Psychiatric Publishing; 2007.

24. Zhu AJ, Walsh BT. Pharmacologic treatment of eating disorders. Can J Psychiatry. 2002;47(3):227-234.

25. Aigner M, Treasure J, Kaye W, Kasper S. World Federation of Societies of Biological Psychiatry (WFSBP) guidelines for the pharmacological treatment of eating disorders. World J Biol Psychiatry. 2011;12(6):400-443.

26. American Psychiatric Association. Treatment of patients with eating disorders, third edition. American Psychiatric Association. Am J Psychiatry. 2006;163(Suppl 7):4-54.

27. National Institute for Health and Clinical Excellence. Eating Disorders. Core Interventions in the Treatment and Managment of Anorexia Nervosa, Bulimia Nervosa and Related Eating Disorders. Clinical Guideline No 9. London, UK: National Institute for Health and Clinical Excellence; 2004.

28. Swanson SA, Crow SJ, Le Grange D, Swendsen J, Merikangas KR. Prevalence and correlates of eating disorders in adolescents: Results from the national comorbidity survey replication adolescent supplement. Arch Gen Psychiatry. 2011;68(7):714-723.

29. Devlin MJ, Goldfein JA, Dobrow I. What is this thing called BED? Current status of binge eating disorder nosology. Int $J$ Eat Disord. 2003;34 Suppl:S2-S18.

30. Grilo CM, Masheb RM. Onset of dieting versus binge eating in outpatients with binge eating disorder. Int J Obes Relat Metab Disord. 2000;24(4):404-409.

31. Walsh BT, Boudreau G. Laboratory studies of binge eating disorder. Int J Eat Disord. 2003;34 Suppl:S30-S38.

32. Schienle A, Schafer A, Hermann A, Vaitl D. Binge-eating disorder: reward sensitivity and brain activation to images of food. Biol Psychiatry. 2009;65(8):654-661.

33. Goldschmidt AB, Le Grange D, Powers P, et al. Eating disorder symptomatology in normal-weight vs obese individuals with binge eating disorder. Obesity (Silver Spring). 2011;19(7):1515-1518.

34. Brandao PP, Garcia-Souza EP, Neves FA, et al. Leptin/adiponectin ratio in obese women with and without binge eating disorder. Neuro Endocrinol Lett. 2010;31(3):353-358.

35. Latner JD, Clyne C. The diagnostic validity of the criteria for binge eating disorder. Int J Eat Disord. 2008;41(1):1-14. 
36. Mobbs O, Iglesias K, Golay A, Van der Linden M. Cognitive deficits in obese persons with and without binge eating disorder. Investigation using a mental flexibility task. Appetite. 2011;57(1):263-271.

37. Wang GJ, Geliebter A, Volkow ND, et al. Enhanced striatal dopamine release during food stimulation in binge eating disorder. Obesity (Silver Spring). 2011;19(8):1601-1608.

38. Striegel-Moore RH, Franko DL. Should binge eating disorder be included in the DSM-V? A critical review of the state of the evidence. Annu Rev Clin Psychol. 2008;4:305-324.

39. Thomas JL, Vartanian LR. Eating disorder not otherwise specified. In: Striegel-Moore RH, Wonderlich SA, Walsh BT, Mitchell JE, editors. Developing an Evidence-Based Classification of Eating Disorders Scientific Findings for DSM-5. Arlington, VA: American Psychiatric Association; 2011.

40. Wilson GT, Sysko R. Frequency of binge eating episodes in bulimia nervosa and binge eating disorder: Diagnostic considerations. Int J Eat Disord. 2009;42(7):603-610.

41. Hudson JI, Coit CE, Lalonde JK, Pope HG Jr. By how much will the proposed new DSM-5 criteria increase the prevalence of binge eating disorder? Int J Eat Disord. 2012;45(1):139-141.

42. McElroy SL, Guerdjikova A, O’Melia A, Mori N, Keck PEJ. Pharmacotherapy of the eating disorders. In: Agras S, editor. Oxford Handbook of Eating Disorders. New York, NY: Oxford University Press Inc; 2010.

43. Yager J. Management of patients with chronic, intractable eating disorders. In: Yager J, Powers PS, editors. Clinical Manual of Eating Disorders. Washington, DC: American Psychiatric Publishing; 2007.

44. Harrold JA, Dovey TM, Blundell JE, Halford JC. CNS regulation of appetite. Neuropharmacology. January 30, 2012. [Epub ahead of print.]

45. Berner LA, Bocarsly ME, Hoebel BG, Avena NM. Pharmacological interventions for binge eating: lessons from animal models, current treatments, and future directions. Curr Pharm Des. 2011;17(12):1180-1187.

46. Mathes WF, Brownley KA, Mo X, Bulik CM. The biology of binge eating. Appetite. 2009;52(3):545-553.

47. Tecott LH, Sun LM, Akana SF, et al. Eating disorder and epilepsy in mice lacking 5-HT ${ }_{2 \mathrm{C}}$ serotonin receptors. Nature. 1995;374(6522): 542-546.

48. Geliebter A, Yahav EK, Gluck ME, Hashim SA. Gastric capacity, test meal intake, and appetitive hormones in binge eating disorder. Physiol Behav. 2004;81(5):735-740.

49. Hargrave SL, Kinzig KP. Repeated gastric distension alters food intake and neuroendocrine profiles in rats. Physiol Behav. 2011;105(4):975-981.

50. Biton V. Weight change and antiepileptic drugs: health issues and criteria for appropriate selection of an antiepileptic agent. Neurologist. 2006;12(3):163-167.

51. Powers PS, Cloak NL. Medication-related weight changes. Impact on treatment of eating disorder patients. In: Yager J, Powers PS, editors. Clinical Manual of Eating Disorders. Washington, DC: American Psychiatric Publishing; 2007.

52. Halford JC, Boyland EJ, Blundell JE, Kirkham TC, Harrold JA Pharmacological management of appetite expression in obesity. Nat Rev Endocrinol. 2010;6(5):255-269.

53. Biton V. Clinical pharmacology and mechanism of action of zonisamide. Clin Neuropharmacol. 2007;30(4):230-240.

54. Clifton PG, Kennett GA. Monoamine receptors in the regulation of feeding behaviour and energy balance. CNS Neurol Disord Drug Targets. 2006;5(3):293-312.

55. Guardia D, Rolland B, Karila L, Cottencin O. GABAergic and glutamatergic modulation in binge eating: therapeutic approach. Curr Pharm Des. 2011;17(14):1396-1409.

56. Husum H, Van Kammen D, Termeer E, Bolwig G, Mathe A. Topiramate normalizes hippocampal neuropeptide Y-LI in flinders sensitive line 'depressed' rats and upregulates neuropeptide $\mathrm{Y}$, galanin, and CRH-LI in the hypothalamus: implications for mood-stabilizing and weight loss-inducing effects. Neuropsychopharmacology. 2003;28(7): 1292-1299.
57. Kwak SE, Kim JE, Kim DS, et al. Differential effects of vigabatrin and zonisamide on the neuropeptide $\mathrm{Y}$ system in the hippocampus of seizure prone gerbil. Neuropeptides. 2005;39(5):507-513.

58. Meister B. Neurotransmitters in key neurons of the hypothalamus that regulate feeding behavior and body weight. Physiol Behav. 2007;92(1-2):263-271.

59. Ravussin E, Smith SR, Mitchell JA, et al. Enhanced weight loss with pramlintide/metreleptin: an integrated neurohormonal approach to obesity pharmacotherapy. Obesity (Silver Spring). 2009;17(9): 1736-1743.

60. Smith SR, Aronne LJ, Burns CM, Kesty NC, Halseth AE, Weyer C. Sustained weight loss following 12-month pramlintide treatment as an adjunct to lifestyle intervention in obesity. Diabetes Care. 2008; 31(9):1816-1823.

61. McElroy SL, Hudson JI, Capece JA, et al. Topiramate for the treatment of binge eating disorder associated with obesity: a placebo-controlled study. Biol Psychiatry. 2007;61(9):1039-1048.

62. Wilfley DE, Crow SJ, Hudson JI, et al. Efficacy of sibutramine for the treatment of binge eating disorder: a randomized multicenter placebo-controlled double-blind study. Am J Psychiatry. 2008;165(1): 51-58.

63. Aronne LJ, Powell AG, Apovian CM. Emerging pharmacotherapy for obesity. Expert Opin Emerg Drugs. 2011;16(3):587-596.

64. Chen Z, Yang J, Tobak A. Designing new treatments for depression and anxiety. IDrugs. 2008;11(3):189-197.

65. Fong TM. Development of anti-obesity agents: drugs that target neuropeptide and neurotransmitter systems. Expert Opin Investig Drugs. 2008;17(3):321-325.

66. Halford JC, Boyland EJ, Lawton CL, Blundell JE, Harrold JA. Serotonergic anti-obesity agents: past experience and future prospects. Drugs. 2011;71(17):2247-2255.

67. Johannessen Landmark C, Johannessen SI. Pharmacological management of epilepsy: recent advances and future prospects. Drugs. 2008;68(14):1925-1939.

68. Machado-Vieira R, Salvadore G, DiazGranados N, et al. New therapeutic targets for mood disorders. Scientific World Journal. 2010;10: 713-726.

69. Appolinario JC, McElroy SL. Pharmacological approaches in the treatment of binge eating disorder. Curr Drug Targets. 2004;5(3) 301-307.

70. Bacaltchuk J, Hay P. Antidepressants versus placebo for people with bulimia nervosa. Cochrane Database Syst Rev. 2003;4:CD003391.

71. Horne RL, Ferguson JM, Pope HG Jr, et al. Treatment of bulimia with bupropion: a multicenter controlled trial. J Clin Psychiatry. 1988;49(7):262-266.

72. Shapiro JR, Berkman ND, Brownley KA, Sedway JA, Lohr KN, Bulik CM. Bulimia nervosa treatment: a systematic review of randomized controlled trials. Int J Eat Disord. 2007;40(4):321-336.

73. Monteleone P, Tortorella A, Castaldo E, Maj M. Association of a functional serotonin transporter gene polymorphism with binge eating disorder. Am J Med Genet B Neuropsychiatr Genet. 2006;141B(1):7-9.

74. Latagliata EC, Patrono E, Puglisi-Allegra S, Ventura R. Food seeking in spite of harmful consequences is under prefrontal cortical noradrenergic control. BMC Neurosci. 2010;11:15.

75. Alger SA, Schwalberg MD, Bigaouette JM, Michalek AV, Howard LJ. Effect of a tricyclic antidepressant and opiate antagonist on binge-eating behavior in normoweight bulimic and obese, binge-eating subjects. Am J Clin Nutr. 1991;53(4):865-871.

76. Arnold LM, McElroy SL, Hudson JI, Welge JA, Bennett AJ, Keck PE. A placebo-controlled, randomized trial of fluoxetine in the treatment of binge-eating disorder. J Clin Psychiatry. 2002;63(11): 1028-1033.

77. Grilo CM, Masheb RM, Wilson GT. Efficacy of cognitive behavioral therapy and fluoxetine for the treatment of binge eating disorder: a randomized double-blind placebo-controlled comparison. Biol Psychiatry. 2005;57(3):301-309. 
78. Guerdjikova AI, McElroy SL, Kotwal R, et al. High-dose escitalopram in the treatment of binge-eating disorder with obesity: a placebo-controlled monotherapy trial. Hum Psychopharmacol. 2008;23(1):1-11.

79. Guerdjikova AI, McElroy SL, Winstanley EL, et al. Duloxetine in the treatment of binge eating disorder with depressive disorders: a placebocontrolled trial. Int J Eat Disord. 2012;45(2):281-289.

80. Hudson JI, McElroy SL, Raymond NC, et al. Fluvoxamine in the treatment of binge-eating disorder: a multicenter placebocontrolled, double-blind trial. Am J Psychiatry. 1998;155(12): $1756-1762$.

81. Laederach-Hofmann K, Graf C, Horber F, et al. Imipramine and diet counseling with psychological support in the treatment of obese binge eaters: a randomized, placebo-controlled double-blind study. Int $J$ Eat Disord. 1999;26(3):231-244.

82. McElroy SL, Casuto LS, Nelson EB, et al. Placebo-controlled trial of sertraline in the treatment of binge eating disorder. Am J Psychiatry. 2000;157(6):1004-1006.

83. McElroy SL, Arnold LM, Shapira NA, et al. Topiramate in the treatment of binge eating disorder associated with obesity: a randomized, placebo-controlled trial. Am J Psychiatry. 2003;160(2):255-261.

84. Pearlstein T, Spurell E, Hohlstein LA, et al. A double-blind, placebocontrolled trial of fluvoxamine in binge eating disorder: a high placebo response. Arch Womens Ment Health. 2003;6(2):147-151.

85. McCann UD, Agras WS. Successful treatment of nonpurging bulimia nervosa with desipramine: a double-blind, placebo-controlled study. Am J Psychiatry. 1990;147(11):1509-1513.

86. Devlin MJ, Goldfein JA, Petkova E, et al. Cognitive behavioral therapy and fluoxetine as adjuncts to group behavioral therapy for binge eating disorder. Obes Res. 2005;13(6):1077-1088.

87. Grilo CM, Masheb RM, Salant SL. Cognitive behavioral therapy guided self-help and orlistat for the treatment of binge eating disorder: a randomized, double-blind, placebo-controlled trial. Biol Psychiatry. 2005;57(10):1193-1201.

88. Brownley KA, Berkman ND, Sedway JA, Lohr KN, Bulik CM. Binge eating disorder treatment: a systematic review of randomized controlled trials. Int J Eat Disord. 2007;40(4):337-348.

89. Stefano SC, Bacaltchuk J, Blay SL, Appolinario JC. Antidepressants in short-term treatment of binge eating disorder: systematic review and meta-analysis. Eat Behav. 2008;9(2):129-136.

90. Grilo CM, Masheb RM, Crosby RD. Predictors and moderators of response to cognitive behavioral therapy and medication for the treatment of binge eating disorder. J Consult Clin Psychol. January 30, 2012. [Epub ahead of print.]

91. Fichter MM, Kruger R, Rief W, Holland R, Dohne J. Fluvoxamine in prevention of relapse in bulimia nervosa: effects on eatingspecific psychopathology. J Clin Psychopharmacol. 1996;16(1): 9-18.

92. Romano SJ, Halmi KA, Sarkar NP, Koke SC, Lee JS. A placebocontrolled study of fluoxetine in continued treatment of bulimia nervosa after successful acute fluoxetine treatment. Am J Psychiatry. 2002;159(1):96-102.

93. Leombruni P, Piero A, Brustolin A, et al. A 12 to 24 weeks pilot study of sertraline treatment in obese women binge eaters. Hum Psychopharmacol. 2006;21(3):181-188.

94. Leombruni P, Piero A, Lavagnino L, Brustolin A, Campisi S, Fassino S. A randomized, double-blind trial comparing sertraline and fluoxetine 6-month treatment in obese patients with binge eating disorder. Prog Neuropsychopharmacol Biol Psychiatry. 2008;32(6): 1599-1605.

95. Devlin MJ, Goldfein JA, Petkova E, Liu L, Walsh BT. Cognitive behavioral therapy and fluoxetine for binge eating disorder: two-year follow-up. Obesity (Silver Spring). 2007;15(7):1702-1709.

96. Calandra C, Russo RG, Luca M. Bupropion versus sertraline in the treatment of depressive patients with binge eating disorder: retrospective cohort study. Psychiatr Q. September 17, 2011. [Epub ahead of print.]
97. Malhotra S, King KH, Welge JA, Brusman-Lovins L, McElroy SL. Venlafaxine treatment of binge-eating disorder associated with obesity: a series of 35 patients. J Clin Psychiatry. 2002;63(9):802-806.

98. Bailer UF, Bloss CS, Frank GK, et al. 5-HT $1 \mathrm{~A}$ receptor binding is increased after recovery from bulimia nervosa compared with control women and is associated with behavioral inhibition in both groups. Int J Eat Disord. 2011;44(6):477-487.

99. Garattini S. Biological actions of drugs affecting serotonin and eating. Obes Res. 1995;3 Suppl 4:463S-470S.

100. Colman E. Anorectics on trial: a half century of federal regulation of prescription appetite suppressants. Ann Intern Med. 2005;143(5): 380-385.

101. Gardin JM, Schumacher D, Constantine G, Davis KD, Leung C, Reid CL. Valvular abnormalities and cardiovascular status following exposure to dexfenfluramine or phentermine/fenfluramine. JAMA. 2000;283(13):1703-1709.

102. Stunkard A, Berkowitz R, Tanrikut C, Reiss E, Young L. D-fenfluramine treatment of binge eating disorder. Am J Psychiatry. 1996;153(11):1455-1459.

103. Padwal RS, Majumdar SR. Drug treatments for obesity: orlistat, sibutramine, and rimonabant. Lancet. 2007;369(9555):71-77.

104. James WP, Caterson ID, Coutinho W, et al. Effect of sibutramine on cardiovascular outcomes in overweight and obese subjects. $N$ Engl J Med. 2010;363(10):905-917.

105. Appolinario JC, Bacaltchuk J, Sichieri R, et al. A randomized, double-blind, placebo-controlled study of sibutramine in the treatment of binge-eating disorder. Arch Gen Psychiatry. 2003;60(11): 1109-1116.

106. Milano W, Petrella C, Casella A, Capasso A, Carrino S, Milano L. Use of sibutramine, an inhibitor of the reuptake of serotonin and noradrenaline, in the treatment of binge eating disorder: A placebocontrolled study. Adv Ther. 2005;22(1):25-31.

107. Franzoi SL, Shields SA. The Body Esteem Scale: multidimensional structure and sex differences in a college population. J Pers Assess. 1984;48(2):173-178.

108. Golay A, Laurent-Jaccard A, Habicht F, et al. Effect of orlistat in obese patients with binge eating disorder. Obes Res. 2005;13(10): 1701-1708.

109. Fernandez-Aranda F, Amor A, Jimenez-Murcia S, GimenezMartinez L, Turon-Gil V, Vallejo-Ruiloba J. Bulimia nervosa and misuse of orlistat: two case reports. Int J Eat Disord. 2001;30(4): 458-461.

110. Hagler Robinson A. Orlistat misuse as purging in a patient with bingeeating disorder. Psychosomatics. 2009;50(2):177-178.

111. Rothman RB, Baumann MH, Dersch CM, et al. Amphetaminetype central nervous system stimulants release norepinephrine more potently than they release dopamine and serotonin. Synapse. 2001;39(1):32-41.

112. Aronne LJ, Halseth AE, Burns CM, Miller S, Shen LZ. Enhanced weight loss following coadministration of pramlintide with sibutramine or phentermine in a multicenter trial. Obesity (Silver Spring). 2010;18(9):1739-1746.

113. Ioannides-Demos LL, Piccenna L, McNeil JJ. Pharmacotherapies for obesity: Past, current, and future therapies. J Obes. 2011;2011: 179674.

114. Alger SA, Malone M, Cerulli J, Fein S, Howard L. Beneficial effects of pharmacotherapy on weight loss, depressive symptoms, and eating patterns in obese binge eaters and non-binge eaters. Obes Res. 1999;7(5):469-476.

115. Devlin MJ, Goldfein JA, Carino JS, Wolk SL. Open treatment of overweight binge eaters with phentermine and fluoxetine as an adjunct to cognitive-behavioral therapy. Int J Eat Disord. 2000;28(3): $325-332$.

116. Green RS, Rau JH. Treatment of compulsive eating disturbances with anticonvulsant medication. Am J Psychiatry. 1974;131(4): $428-432$. 
117. Hudson JI, Pope HG Jr. The role of anticonvulsants in the treatment of bulimia. In: McElroy SL, Pope HG Jr, editors. Use of Anticonvulsants in Psychiatry. Clifton, NJ: Oxford Health Care; 1988.

118. Rau JH, Struve FA, Green RS. Electroencephalographic correlates of compulsive eating. Clin Electroencephalogr. 1979;10(4): 180-189.

119. Moore SL, Rakes SM. Binge eating - therapeutic response to diphenylhydantoin: case report. J Clin Psychiatry. 1982;43(9): 385-386.

120. McElroy SL, Keck PE Jr, Pope HG Jr. Antiepileptic Drugs to Treat Psychiatric Disorders. New York, NY: Informa Healthcare; 2008.

121. Gadde KM, Franciscy DM, Wagner HR 2nd, Krishnan KR. Zonisamide for weight loss in obese adults: a randomized controlled trial. JAMA. 2003;289(14):1820-1825.

122. McElroy SL, Guerdjikova AI, Keck PEJ, Pope HG Jr, Hudson JI. Antiepileptic drugs in obesity, psychotropic-associated weight gain, and eating disorders. In: McElroy SL, Keck PEJ, Post RM, editors. Antiepileptic Drugs to Treat Psychiatric Disorders. New York, NY: Informa Healthcare; 2008.

123. Olive MF, Cleva RM, Kalivas PW, Malcolm RJ. Glutamatergic medications for the treatment of drug and behavioral addictions. Pharmacol Biochem Behav. 2012;100(4):801-810.

124. McElroy SL, Keck PE Jr. Topiramate. In: Schatzberg AF, Nemeroff CB, editors. The American Psychiatric Publishing Textbook of Psychopharmacology. Washington, DC: American Psychiatric Publishing Inc; 2009.

125. Bray GA, Hollander P, Klein S, et al. A 6-month randomized, placebocontrolled, dose-ranging trial of topiramate for weight loss in obesity. Obes Res. 2003;11(6):722-733.

126. Wilding J, Van Gaal L, Rissanen A, Vercruysse F, Fitchet M. A randomized double-blind placebo-controlled study of the long-term efficacy and safety of topiramate in the treatment of obese subjects. Int J Obes Relat Metab Disord. 2004;28(11):1399-1410.

127. Tonstad S, Tykarski A, Weissgarten J, et al. Efficacy and safety of topiramate in the treatment of obese subjects with essential hypertension. Am J Cardiol. 2005;96(2):243-251.

128. Allison DB, Gadde KM, Garvey WT, et al. Controlled-release phentermine/topiramate in severely obese adults: a randomized controlled trial (EQUIP). Obesity (Silver Spring). 2011;20(2): 330-342.

129. Gadde KM, Allison DB, Ryan DH, et al. Effects of low-dose, controlled-release, phentermine plus topiramate combination on weight and associated comorbidities in overweight and obese adults (CONQUER): a randomised, placebo-controlled, phase 3 trial. Lancet. 2011;377(9774):1341-1352.

130. Garvey WT, Ryan DH, Look M, et al. Two-year sustained weight loss and metabolic benefits with controlled-release phentermine/ topiramate in obese and overweight adults (SEQUEL): a randomized, placebo-controlled, phase 3 extension study. Am J Clin Nutr. 2012;95(2):297-308.

131. Barratt ES, Stanford MS. Impulsiveness. In: Cooper GC, editor. Impulsiveness in Personality Characteristics of the Personality Disordered Client. New York, NY: Wiley; 1995.

132. Claudino AM, de Oliveira IR, Appolinario JC, et al. Double-blind, randomized, placebo-controlled trial of topiramate plus cognitive-behavior therapy in binge-eating disorder. J Clin Psychiatry. 2007;68(9): 1324-1332.

133. McElroy SL, Shapira NA, Arnold LM, et al. Topiramate in the longterm treatment of binge-eating disorder associated with obesity. J Clin Psychiatry. 2004;65(11):1463-1469.

134. De Bernardi C, Ferraris S, D'Innella P, Do F, Torre E. Topiramate for binge eating disorder. Prog Neuropsychopharmacol Biol Psychiatry. 2005;29(2):339-341.

135. Dolberg OT, Barkai G, Gross Y, Schreiber S. Differential effects of topiramate in patients with traumatic brain injury and obesity - a case series. Psychopharmacology (Berl). 2005;179(4):838-845.
136. Kotwal R, Guerdjikova A, McElroy SL, Keck PE Jr. Lithium augmentation of topiramate for bipolar disorder with comorbid binge eating disorder and obesity. Hum Psychopharmacol. 2006;21(7):425-431.

137. Schmidt do Prado-Lima PA, Bacaltchuck J. Topiramate in treatmentresistant depression and binge-eating disorder. Bipolar Disord. 2002;4(4):271-273.

138. Shapira NA, Goldsmith TD, McElroy SL. Treatment of binge-eating disorder with topiramate: a clinical case series. J Clin Psychiatry. 2000;61(5):368-372.

139. Guerdjikova AI, Kotwal R, McElroy SL. Response of recurrent binge eating and weight gain to topiramate in patients with binge eating disorder after bariatric surgery. Obes Surg. 2005;15(2):273-277.

140. Zilberstein B, Pajecki D, Garcia de Brito AC, Gallafrio ST, Eshkenazy R, Andrade CG. Topiramate after adjustable gastric banding in patients with binge eating and difficulty losing weight. Obes Surg. 2004;14(6):802-805.

141. Colom F, Vieta E, Benabarre A, et al. Topiramate abuse in a bipolar patient with an eating disorder. J Clin Psychiatry. 2001;62(6):475-476.

142. McElroy SL, Kotwal R, Guerdjikova AI, et al. Zonisamide in the treatment of binge eating disorder with obesity: a randomized controlled trial. J Clin Psychiatry. 2006;67(12):1897-1906.

143. Orexigen. Available from: http://www.orexigen.com/candidates. Accessed February 17, 2012.

144. Gadde KM, Yonish GM, Foust MS, Wagner HR. Combination therapy of zonisamide and bupropion for weight reduction in obese women: a preliminary, randomized, open-label study. J Clin Psychiatry. 2007;68(8):1226-1229.

145. McElroy SL, Kotwal R, Hudson JI, Nelson EB, Keck PE. Zonisamide in the treatment of binge-eating disorder: an open-label, prospective trial. J Clin Psychiatry. 2004;65(1):50-56.

146. Guerdjikova AI, McElroy SL, Welge JA, Nelson E, Keck PE, Hudson JI. Lamotrigine in the treatment of binge-eating disorder with obesity: a randomized, placebo-controlled monotherapy trial. Int Clin Psychopharmacol. 2009;24(3):150-158.

147. Merideth CH. A single-center, double-blind, placebo-controlled evaluation of lamotrigine in the treatment of obesity in adults. J Clin Psychiatry. 2006;67(2):258-262.

148. Greenway FL, Dahms WT, Bray GA. Phenytoin as a treatment of obesity associated with compulsive eating. Current Therapeutic Research. 1977;21:338-342.

149. Wermuth BM, Davis KL, Hollister LE, Stunkard AJ. Phenytoin treatment of the binge-eating syndrome. Am J Psychiatry. 1977;134(11): 1249-1253.

150. Leombruni P, Gastaldi F, Lavagnino L, Fassino S. Oxcarbazepine for the treatment of binge eating disorder: a case series. Adv Ther. 2008;25(7):718-724.

151. Bello NT, Hajnal A. Acute methylphenidate treatments reduce sucrose intake in restricted-fed bingeing rats. Brain Res Bull. 2006; 70(4-6):422-429.

152. Ong YL, Checkley SA, Russell GF. Suppression of bulimic symptoms with methylamphetamine. Br J Psychiatry. 1983;143:288-293.

153. Drimmer EJ. Stimulant treatment of bulimia nervosa with and without attention-deficit disorder: three case reports. Nutrition. 2003;19(1): 76-77.

154. Dukarm CP. Bulimia nervosa and attention deficit hyperactivity disorder: a possible role for stimulant medication. J Womens Health (Larchmt). 2005;14(4):345-350.

155. Schweickert LA, Strober M, Moskowitz A. Efficacy of methylphenidate in bulimia nervosa comorbid with attention-deficit hyperactivity disorder: a case report. Int J Eat Disord. 1997;21(3):299-301.

156. Sokol MS, Gray NS, Goldstein A, Kaye WH. Methylphenidate treatment for bulimia nervosa associated with a cluster B personality disorder. Int J Eat Disord. 1999;25(2):233-237.

157. Silveira RO, Zanatto V, Appolinario JC, Kapczinski F. An open trial of reboxetine in obese patients with binge eating disorder. Eat Weight Disord. 2005;10(4):e93-e96. 
158. Davis C, Levitan RD, Kaplan AS, et al. Dopamine transporter gene (DAT1) associated with appetite suppression to methylphenidate in a case-control study of binge eating disorder. Neuropsychopharmacology. 2007;32(10):2199-2206.

159. O'Brien CP. Anticraving agents for the treatment of addictive disorders. Curr Psychiatry Rep. 2004;6(5):321-322.

160. Gearhardt AN, Yokum S, Orr PT, Stice E, Corbin WR, Brownell KD. Neural correlates of food addiction. Arch Gen Psychiatry. 2011;68(8): 808-816.

161. Gearhardt AN, White MA, Potenza MN. Binge eating disorder and food addiction. Curr Drug Abuse Rev. 2011;4(3):201-207.

162. McElroy SL, Guerdjikova AI, Winstanley EL, et al. Acamprosate in the treatment of binge eating disorder: A placebo-controlled trial. Int $J$ Eat Disord. 2011;44(1):81-90.

163. Mitchell JE, Christenson G, Jennings J, et al. A placebo-controlled, double-blind crossover study of naltrexone hydrochloride in outpatients with normal weight bulimia. J Clin Psychopharmacol. 1989;9(2):94-97.

164. Marrazzi MA, Bacon JP, Kinzie J, Luby ED. Naltrexone use in the treatment of anorexia nervosa and bulimia nervosa. Int Clin Psychopharmacol. 1995;10(3):163-172.

165. Jonas JM, Gold MS. The use of opiate antagonists in treating bulimia: a study of low-dose versus high-dose naltrexone. Psychiatry Res. 1988;24(2):195-199.

166. Raingeard I, Courtet P, Renard E, Bringer J. Naltrexone improves blood glucose control in type 1 diabetic women with severe and chronic eating disorders. Diabetes Care. 2004;27(3):847-848.

167. Drewnowski A, Krahn DD, Demitrack MA, Nairn K, Gosnell BA. Naloxone, an opiate blocker, reduces the consumption of sweet high-fat foods in obese and lean female binge eaters. Am J Clin Nutr. 1995;61(6):1206-1212.

168. Greenway FL, Dunayevich E, Tollefson G, et al. Comparison of combined bupropion and naltrexone therapy for obesity with monotherapy and placebo. J Clin Endocrinol Metab. 2009;94(12):4898-4906.

169. Greenway FL, Fujioka K, Plodkowski RA, et al. Effect of naltrexone plus bupropion on weight loss in overweight and obese adults (COR-I): a multicentre, randomised, double-blind, placebo-controlled, phase 3 trial. Lancet. 2010;376(9741):595-605.

170. Wadden TA, Foreyt JP, Foster GD, et al. Weight loss with naltrexone SR/bupropion SR combination therapy as an adjunct to behavior modification: the COR-BMOD trial. Obesity (Silver Spring). 2011;19(1):110-120.

171. Marrazzi MA, Markham KM, Kinzie J, Luby ED. Binge eating disorder: response to naltrexone. Int J Obes Relat Metab Disord. 1995;19(2):143-145

172. Meyer F. Alleviation of both binge eating and sexual dysfunction with naltrexone. J Clin Psychopharmacol. 2008;28(6):722-723.

173. Neumeister A, Winkler A, Wober-Bingol C. Addition of naltrexone to fluoxetine in the treatment of binge eating disorder. Am J Psychiatry. 1999;156(5):797.

174. Hillemacher T, Heberlein A, Muschler MA, Bleich S, Frieling H. Opioid modulators for alcohol dependence. Expert Opin Investig Drugs. 2011;20(8):1073-1086.

175. Alkermes. Alkermes announces results from Phase 2 study of ALKS 33 for treatment of binge eating disorder. Available from: http://phx. corporate-ir.net/phoenix.zhtml?c=92211\&p=irol-corporateNewsArti cle\&ID=1582921\&highlight. Accessed March 1, 2012.

176. Blednov YA, Adron Harris R. Metabotropic glutamate receptor 5 (mGluR5) regulation of ethanol sedation, dependence and consumption: relationship to acamprosate actions. Int J Neuropsychopharmacol. 2008;11(6):775-793.

177. Hermanussen M, Tresguerres JA. A new anti-obesity drug treatment: first clinical evidence that antagonising glutamate-gated $\mathrm{Ca} 2+$ ion channels with memantine normalises binge-eating disorders. Econ Hum Biol. 2005;3(2):329-337.
178. Brennan BP, Roberts JL, Fogarty KV, Reynolds KA, Jonas JM, Hudson JI. Memantine in the treatment of binge eating disorder: an open-label, prospective trial. Int J Eat Disord. 2008;41(6):520-526.

179. Zaharna M, Dimitriu A, Guilleminault C. Expert opinion on pharmacotherapy of narcolepsy. Expert Opin Pharmacother. 2010;11(10): 1633-1645.

180. Pardi D, Black J. Gamma-hydroxybutyrate/sodium oxybate: neurobiology, and impact on sleep and wakefulness. CNS Drugs. 2006;20(12):993-1018.

181. Fortuyn HA, Swinkels S, Buitelaar J, et al. High prevalence of eating disorders in narcolepsy with cataplexy: a case-control study. Sleep. 2008;31(3):335-341.

182. McElroy SL, Guerdjikova AI, Winstanley EL, et al. Sodium oxybate in the treatment of binge eating disorder: an open-label, prospective study. Int J Eat Disord. 2011;44(3):262-268.

183. Broft AI, Spanos A, Corwin RL, et al. Baclofen for binge eating: an open-label trial. Int J Eat Disord. 2007;40(8):687-691.

184. Brewerton TD, Shannon M. Possible clozapine exacerbation of bulimia nervosa. Am J Psychiatry. 1992;149(10):1408-1409.

185. Gebhardt S, Haberhausen M, Krieg JC, et al. Clozapine/ olanzapine-induced recurrence or deterioration of binge eating-related eating disorders. J Neural Transm. 2007;114(8):1091-1095.

186. Theisen FM, Linden A, Konig IR, Martin M, Remschmidt H, Hebebrand J. Spectrum of binge eating symptomatology in patients treated with clozapine and olanzapine. J Neural Transm. 2003; 110(1):111-121.

187. Jacobs-Pilipski MJ, Wilfley DE, Crow SJ, et al. Placebo response in binge eating disorder. Int J Eat Disord. 2007;40(3):204-211.

188. Guerdjikova AI, McElroy SL. Binge eating disorder pharmacotherapy clinical trials - who is left out? Eur Eat Disord Rev. 2009;17(2): 101-108

189. Berlim MT, Fleck MP, Turecki G. Current trends in the assessment and somatic treatment of resistant/refractory major depression: an overview. Ann Med. 2008;40(2):149-159.

190. Brambilla F, Samek L, Company M, Lovo F, Cioni L, Mellado C. Multivariate therapeutic approach to binge-eating disorder: Combined nutritional, psychological and pharmacological treatment. Int Clin Psychopharmacol. 2009;24(6):312-317.

191. Zarate CA, Manji HK. Riluzole in psychiatry: a systematic review of the literature. Expert Opin Drug Metab Toxicol. 2008;4(9): 1223-1234.

192. Fidler MC, Sanchez M, Raether B, et al. A one-year randomized trial of lorcaserin for weight loss in obese and overweight adults: the BLOSSOM trial. J Clin Endocrinol Metab. 2011;96(10):3067-3077.

193. Astrup A, Madsbad S, Breum L, Jensen TJ, Kroustrup JP, Larsen TM. Effect of tesofensine on bodyweight loss, body composition, and quality of life in obese patients: a randomised, double-blind, placebocontrolled trial. Lancet. 2008;372(9653):1906-1913.

194. Field BC, Wren AM, Cooke D, Bloom SR. Gut hormones as potential new targets for appetite regulation and the treatment of obesity. Drugs. 2008;68(2):147-163.

195. Heal DJ, Smith SL, Fisas A, Codony X, Buschmann H. Selective 5-HT6 receptor ligands: progress in the development of a novel pharmacological approach to the treatment of obesity and related metabolic disorders. Pharmacol Ther. 2008;117(2):207-231.

196. Rivera G, Bocanegra-Garcia V, Galiano S, et al. Melanin-concentrating hormone receptor 1 antagonists: a new perspective for the pharmacologic treatment of obesity. Curr Med Chem. 2008;15(10): 1025-1043.

197. Smith SR, Prosser WA, Donahue DJ, et al. Lorcaserin (APD356), a selective 5-HT(2C) agonist, reduces body weight in obese men and women. Obesity (Silver Spring). 2009;17(3):494-503.

198. Smith SR, Weissman NJ, Anderson CM, et al. Multicenter, placebocontrolled trial of lorcaserin for weight management. $N$ Engl J Med. 2010;363(3):245-256. 
199. Tran P, Skolnick P, Czobor P, et al. Efficacy and tolerability of the novel triple reuptake inhibitor amitifadine in the treatment of patients with major depressive disorder: a randomized, double-blind, placebocontrolled trial. J Psychiatr Res. 2012;46(1):64-71.

200. Sysko R, Hildebrandt T, Wilson GT, Wilfley DE, Agras WS. Heterogeneity moderates treatment response among patients with binge eating disorder. J Consult Clin Psychol. 2010;78(5):681-690.
201. Bulik CM, Hebebrand J, Keski-Rahkonen A, et al. Genetic epidemiology, endophenotypes, and eating disorder classification. Int J Eat Disord. 2007;40 Suppl:S52-S60.

Therapeutics and Clinical Risk Management

\section{Publish your work in this journal}

Therapeutics and Clinical Risk Management is an international, peerreviewed journal of clinical therapeutics and risk management, focusing on concise rapid reporting of clinical studies in all therapeutic areas, outcomes, safety, and programs for the effective, safe, and sustained use of medicines. This journal is indexed on PubMed Central, CAS,

Submit your manuscript here: http://www.dovepress.com/therapeutics-and-clinical-risk-management-journal
EMBase, Scopus and the Elsevier Bibliographic databases. The manuscript management system is completely online and includes a very quick and fair peer-review system, which is all easy to use. Visit http://www.dovepress.com/testimonials.php to read real quotes from published authors. 